\title{
Article
}

\section{The Impact of Self-Efficacy on Feelings and Task Performance of Academic and Teaching Staff in Bahrain during COVID-19: Analysis by SEM and ANN}

\author{
Ghilan Al-Madhagy Taufiq-Hail ${ }^{1,2, * \mathbb{C}}$, Adel Sarea $^{3}$ and Iqbal Thonse Hawaldar ${ }^{4}$ \\ 1 Institute for Advanced and Smart Digital Opportunities (IASDO), School of Computing (SOC), \\ University Utara Malaysia (UUM), Sintok 06010, Malaysia \\ 2 College of Business (COB), University of Buraimi (UOB), Al Buraimi Governorate 890, Oman \\ 3 College of Business and Finance, Ahlia University, Manama 10878, Bahrain; Adelsarea@yahoo.com \\ 4 Department of Accounting \& Finance, College of Business Administration, Kingdom University, \\ Riffa 40434, Bahrain; i.hawaldar@ku.edu.bh \\ * Correspondence: towfeeq2k5@yahoo.com or taufiq.h@uob.edu.om
}

Citation: Taufiq-Hail, G.A.-M.; Sarea

A.; Hawaldar, I.T. The Impact of Self-Efficacy on Feelings and Task Performance of Academic and Teaching Staff in Bahrain during COVID-19: Analysis by SEM and ANN. J. Open Innov. Technol. Mark. Complex. 2021, 7, 224. https:// doi.org/10.3390/joitmc7040224

Received: 30 June 2021

Accepted: 11 October 2021

Published: 8 November 2021

Publisher's Note: MDPI stays neutral with regard to jurisdictional claims in published maps and institutional affiliations.

Copyright: (C) 2021 by the authors Licensee MDPI, Basel, Switzerland. This article is an open access article distributed under the terms and conditions of the Creative Commons Attribution (CC BY) license (https:// creativecommons.org/licenses/by/ $4.0 /)$.

\begin{abstract}
COVID-19 has changed the way we live, communicate and work, as well as altering our feelings. The higher education sector, alongside other sectors, has been severely affected by the pandemic and its serious repercussions. Academic and teaching staff have had to work from home and convert to online teaching, a change which has been met with both negative and positive feelings. The need for new competencies and upskilling, among other challenges, has been encountered. Therefore, the objectives of this study are aligned with exploring the impact of three constructs-selfefficacy, positive feelings and negative feelings_-on the performance of academic and teaching staff at public and private universities in Bahrain during the COVID-19 lockdown. Additionally, the impact of self-efficacy on these feelings was explored. A cross-sectional quantitative survey instrument was developed, validated and distributed using 83 valid responses. A two-way approach was followed to evaluate the model using the partial least squares (PLS-SEM) and multi-layer perceptron-artificial neural network (MLP-ANN) techniques. Tests support the validity, reliability and consistency of the measurement scale, as well as the validity of the postulated model. The results revealed a statistically significant relationship between the three constructs and performance. Interestingly, attention is drawn to the impact of self-efficacy on increasing positive feelings and task performance. The impact of self-efficacy on reducing negative feelings is also evident. Analyses of PLS-SEM augmented by MLP-ANN enhanced our understanding of the relationships and gave more support to the use of dual approach analyses in future research. This research adds to COVID-19 global research and the findings increase the knowledge within the literature. The implications of the study's outcomes should be given attention from higher education authorities and management to raise staff morale and offer training to help sustain performance and mental wellbeing. Lasty, limitations and future directions are discussed.
\end{abstract}

Keywords: artificial neural network; Bahrain; COVID-19; higher education; negative feelings; positive feelings; self-efficacy; task performance

\section{Introduction \\ 1.1. The General Impact of COVID-19 on People's Lives}

From the very beginning, the COVID-19 pandemic turned life upside down around the globe [1], forcing many business entities as well as individuals to face new challenges. Individuals have encountered many difficulties, ranging from self-isolation to looking for essentials [2]. Many businesses closed and others struggled to meet the high demand for health supplies, logistics and people's daily needs [3]. Additionally, the global economy suffered from losses that exceeded USD 50 million, dramatically affecting many industries 
worldwide [4]. The higher education (HE) sector was no exception. More importantly, COVID-19 affected not only physical health, but also created critical mental health issues that threatened wellbeing and prompted changes in behavior [5]. The change of behavior towards negative wellbeing of academic and teaching staff presumably, impacted their performance and needs exploration, given the current global infection. In view of this, [6] proposes deeper introspection and research into the impact of COVID-19 on emotions and social life. In response, this research focuses on the feelings/emotions felt by academic and teaching staff during the pandemic and contributes to the current literature for the better understanding of the consequences of COVID-19 on people's lives [7].

Many regulations and procedures have been imposed to cope with the drastically increasing number of COVID-19 infections. Of course, all procedures have been undertaken under the control of new government policies and regulations to comply with the World Health Organization (WHO) precautionary measures. However, the major change to peoples' lives was social isolation, a term which became widely used in all media [8]. More importantly, social media, government statistics and the proliferation of other media (i.e., heard, seen or read) announcing the number of infected cases or the rapid spread of the pandemic, caused chaos, hysteria and COVID-19 phobia [1,9]. Many countries followed the Chinese initiative of "suspending classes without stopping learning" that switched traditional education into large-scale online teaching [10].

This emergent situation created new challenges and feelings for working individuals in general and academic and teaching staff specifically. The challenges can be summarized as the methods of delivering syllabi while no longer being physically present and the transformation of lectures into a digital format; difficulties were compounded by the sudden emergence of the disease, unreadiness to switch to a completely new way of conveying knowledge to students and the extended time required to achieve tasks assigned to academic and teaching staff that had been straightforward in the past.

In principle, the shifting phases of innovation categories suggested by Roger in the diffusion of innovation theory [11], i.e., innovators, early adopters, early majority, late majority and laggards, became absolute and the dominant shift can be said to have occurred to the innovators and early majority [8]. Yan [8] gave an example of teachers who voluntarily started to use the Zoom platform to continue education from home as a consequence of the dramatic change in teaching. In other words, the sequence of acceptance in shifting into the digital era was not that presumed by Roger's theory. These changes to peoples' lives caused by COVID-19 need further study in different disciplines in order to avoid future losses and preserve human wellbeing.

\subsection{The Rationale behind the Study}

Generally speaking, most research into the effects of the COVID-19 pandemic has focused on students and its negative impact $[5,12-16]$, as well as the impact on HE institutions and their move to virtual online classes $[17,18]$. For instance, a study was conducted by a group of researchers into the psychological effects of COVID-19 on students and university staff [19]. It focused on depression, anxiety and stressful psychological effects in one Spanish university, employing a cross-sectional approach. The study drew attention only to negative emotions or feelings and lacked exploration of positive feelings that helped individuals cope with the consequences of the coronavirus. Similarly, empirical investigation of these effects on performance was neglected. Ali and Dmour [20] focused on assessment and the strategies implemented by UAE universities during the pandemic and recruited students to explore their behavior and performance based on comparison with their previous GPA (grade point average) and CGPA (cumulative GPA) [20]. However, study on the educators was not indicated, even in proposals for future research, although the staff are a crucial building block of the education system. Another example is the work of [21], to measure the happiness of undergraduates and postgraduate students and its relationship with their academic performance during the lockdown. This also examined the gender differences in wellbeing and the level of happiness. They found a relationship 
between students' happiness and their academic achievements and no significant gender differences in the wellbeing and happiness levels. Despite the fact that the research focused on positive feelings in boosting the performance of the students, the role of these positive emotions was not investigated among academic or teaching staff. Hence, the current study considered adding positive feelings to the proposed research model, to investigate their effect on the performance of the academic staff. This also addresses another gap, the context of the study being the Gulf Cooperative Council (GCC) countries, specifically Bahrain.

A number of studies have indeed been conducted in GCC countries with the aim of exploring different aspects of COVID-19's impact. For instance, the work of [22] focused on gaining insights from multidisciplinary academics from the Kingdom of Saudi Arabia and Kuwait, pertaining to their views on the consequences of adaption to COVID-19 and the role of academics in the social and professional challenges. Another qualitative exploratory study implemented by [23] ascertained the opinion of female Saudi graduates on three main issues: their perception of the impact of the Stay-at-Home initiative enforced by the Government of Saudi; the values emerging as manifested by the respondents; and recommendations and possible innovative solutions for facing COVID-19 issues. The main results reveal some of the negative feelings experienced during the pandemic, including fear of infection, loneliness, boredom and financial concerns. However, the empirical investigation of the effects of these negative emotions on performance was not taken into consideration, triggering the current research. In addition, an analytical overview and descriptive study conducted by [17] aimed to identify the responses and adaptations of GCC HE institutions during the COVID-19 era. These adaptations were intended to maintain the business of education, preserve its quality and to bring insight into the responses of resilience, creativity and re-imagining the future. However, the human role, in other words the educators, was not given adequate attention in shedding more light on how the teaching and academic staff coped with the difficulties in order to preserve the educational process. Hence, this is another gap that warrants focus on academic and teaching staff in GCC countries.

To sum up, empirical studies probing the impact of positive and negative emotions of the academic and teaching staff on their performance during the pandemic has not been investigated in depth in GCC countries, specifically Bahrain. The emerging situation during COVID-19 imposes the need to conduct such empirical studies covering the different emotions and feelings of the educators and their influence on performance in GCC countries and worldwide.

The burden and responsibilities on educators increased with respect to family members, as well as the institution and students. The escalating situation, with the need to gain new skills in a distressingly short time, produced negative feelings. On the other hand, positive feelings are also vital in handling such new challenges and changes in performing tasks professionally, efficiently and on time, both to meet the expectations of the institution and to afford self-satisfaction. However, the role of self-efficacy, a key driver in measuring the performance of the academic and teaching staff during COVID-19, has unfortunately not been given sufficient attention in contemporary studies of the impact of the pandemic and social isolation/distance. Hence, self-efficacy was added to the research model to measure its relationship with performance in this exceptional situation.

Based on these emergent issues and to explore the repercussions of COVID-19, this research considers the role of self-efficacy, negative and positive feelings on the performance of the academic and teaching staff of Bahraini HE institutions and explores the role of self-efficacy on the positive and negative feelings to working in the virtual environment. Hence, the research is intended to answer the following questions:

(1) Do negative feelings which emerged during the COVID-19 pandemic lockdown affect the academic and teaching staff in Bahrain in performing their tasks using distance and online teaching applications?

(2) Do positive feelings influence the performance of the academic and teaching staff in Bahrain during the COVID-19 lockdown, based on their own judgment? 
(3) Does self-efficacy have a statistically and significant positive correlation with the performance of HE teaching and academic staff $\mathrm{i}$ in Bahrain during the lockdown?

(4) Does self-efficacy exert a reverse impact on the negative feelings toward the performance of Bahraini HE teaching and academic staff during the lockdown?

(5) Does self-efficacy exert a significant positive effect on the positive feelings of the Bahraini HE teaching and academic staff toward the performance during the lockdown pandemic?

(6) Do the two analysis approaches, PLS-SEM and MLP-ANN, bring new insights, augment and complement each other, based on the literature and empirical implementation in the current research?

To achieve the objectives highlighted by these questions, a research framework is proposed and a developed and distributed questionnaire survey used to collect data from the academic and teaching staff. The remaining sections of this paper are organized as follows. In Section 2, the literature review examines the impact of COVID-19 and its serious repercussions on the transition to online teaching; the hypotheses are proposed; and the artificial neural network definition, architecture and the difference between PLSSEM (partial least squares-sequential equation modeling) and MLP-ANN (multi-layer perceptron-artificial neural network) analysis are presented. Section 3 explains the research methodology and Section 4 the data analysis and results, followed by the discussion. Finally, the conclusion in Section 5 draws together the main outcomes of the study, with implications and suggestions for future directions.

\section{Literature Review and Hypotheses Development}

In this section, the background to the aspects of the swift transition from traditional to online teaching is demonstrated. Then, the development of the hypotheses is explained starting with the definition of each variable. Next, definitions of ANN and architecture and the identification of the number of neurons and hidden layer are explained [7]. Differences and the complementary role of PLS-SEM and ANN analyses are elucidated. The nexus between positive and negative feelings on performance during the COVID-19 outbreak is explored and hypotheses are drawn. Self-efficacy is further demonstrated and hypothesized against performance.

\subsection{COVID-19's Repercussions and the Immediate Transition of the Traditional Teaching and Learning toward Online MethodTeaching}

The unexpected outbreak and continual spread of the coronavirus have brought many changes in our habits, feelings, the way we work, communication and social relationships. The educational process is not immune and teaching and learning activities have changed completely, with new challenges and hardships surfaced as the newness of the virus per se [24]. The GCC countries followed other nations in suspending HE institutions and schools in an effort to curb the spread of the infection, in Bahrain. The early closure of HE institutions and schools started on 25 February 2020 in Bahrain. Following that United Arab Emirates, Saudi Arabia, Qatar, Kuwait and, finally, Oman on March 2020 [25]. The total number of GCC learners affected was 12,085,898, of which the majority were in Saudi (69.5\%) and the fewest in Qatar (1.44\%) [25]. Almost all the HE institutions adopted learning management systems (LMS) and were equipped with technological tools to continue the educational process. All student registration was performed online and different resources were provided to handle the sudden change to online teaching.

Although it is widely accepted that during crises human nature seeks to adapt to the new situation, with innovation, this was not the case with the rapidly changing COVID-19 situation [26]. Innovation develops gradually and does not come suddenly into practice before it matures [26]. Although the change from conventional methods to blended and online education (i.e., synchronous and asynchronous) worldwide, was proposed a long time ago, the sudden shift to online was unplanned and unexpected by the majority of educational institutions. Their suspension and closure and the cancellation of many on-campus 
activities, such as lectures, conferences, workshops and sports activities, necessitated the transition to online to curb the spread of infection by breaking the chain of transmission [27]. In other words, the teaching/learning activities were involuntarily changed.

The nature of business and society changed dramatically as a result of the COVID-19 outbreak, the lockdown and its repercussions, with unprecedented challenges to all aspects of life [3]. The working staff in all sectors, which the academic and teaching staff are no exception, have faced new challenges in the way they work and they retreated to the sanctity of the private home. In addition, the social distancing became obligatory as schools and universities suspended or completely closed that made working online a must [24] and rendered a panacea to survive the education process [6]. Changing work habits to do working tasks at home while facing the feelings of uncertainty and trying to maintain ourselves and colleagues motivated are other aspects of the impact of COVID-19 [28]. Furthermore, how to manage the work tasks (i.e., work-based role) in addition to in-house responsibilities (i.e., home-based role) created tensions and accumulated burden to compete with [28]. In addition, privacy has been distracted by holding meetings inside the private rooms/home-office and finding oneself in the spot to see children moving around or pits.

Interestingly, individuals began to work longer hours at their computers as the boundary between home and work dissolved [29]. Previous writers have emphasized the significant role of the emotions in virtual environments, especially with the mixed and turbulent feelings of frustration, fear and uncertainty caused by the lockdown [28]. Virtual, online teaching/learning replaced face-to-face contact and the physical presence in front of the students, where body language and facial expressions played a vital role in communication between the teachers and learners [30]. This situation holds for most HE institutions in developing countries, with the exception of the few that already had adopted mixed methods of online and traditional learning/teaching. For example, Bisht, Jasola and Bisht [31] demonstrated that the transition from traditional teaching to the online mode went smoothly as a result of having a digital curriculum in the form of massive open online courses (MOOC), recorded or streamed for use by students. These authors [31] contend that this smooth transition ensures continuity in the teaching/learning process, engagement of students in virtual classes and has the benefit of minimizing the negative psychological effects of COVID-19.

In sum, there are differences between the two modes of teaching - the traditional and the online - that can be summarized as follows: In conventional/traditional mode the body language, the face-to-face expression and the direct communication between the tutor and the learner played a vital role in the education process. On the other hand, in online mode (i.e., synchronous or asynchronous) there are physical boundaries between the educator and student, the recognition of the students' understanding by the facial expression is lacked, the time for preparation of lessons increased, the glimpse of the student movements is difficult and the disturbance in the virtual class may be faced either for the learner or the tutor [30] from home dwellers. More importantly, the online distance learning requires the student to have self-discipline, eagerness to learn and ask for assistance, self-motivation and seriousness to learn [32]. Noteworthy, switching toward the online teaching is coupled with online assessment, is another obstacle. The educators find it difficult to comply with the accustomed method of evaluation and the emergent way of evaluations that raised number of questions: Are we fairly evaluating the students? Do they really deserve marks given to them? In addition, are the quizzes or online exams achieving the goal of educational knowledge attainment?

The swift transition to online teaching might be expected to provoke negative emotions and degrade the performance of staff. Conversely, despite the difficult situation, socialisolation and complete lockdown, positive feelings may exist; for example, institutions' and teachers' attempts to maintain morale, exploration of social media to release stress, in-house sporting activities, communicating with colleagues and friends by social media, receiving positive news of recoveries and spending more time talking to children and spouses. 
Already having the proper skills, technical competencies and intellectual capabilities to adapt to the online pedagogy and the strong and indomitable will to adjust to the new situation of the lockdown, are traits which might be expected to encourage greater productivity. The self-efficacy reflected in these features should reduce negative feelings and strengthen the positive ones, in turn maintaining task performance if not boosting it. For this reason, one of the study's objectives is to evaluate the relationship between self-efficacy on the one hand and the positive/negative feelings and task performance on the other hand, among teaching and academic staff during COVID-19.

In addition, as indicated in literature, Tsui et al. [26] explained the sudden switching to online mode in a very short time-adding to that the stress emerged that is mixed up with fear and anxiety of being infected alongside with upskilling to new e-learning tools and software-has created much more obstacles that might degrade the performance in teaching the academic syllabus. In addition, the online learning differs from the traditional teaching/learning paradigm. That is, unlike the traditional mode of teaching, in online mode the tutor is apparently unable to glamps what the students do during the lesson. Are they showing boredom, tiredness, or confusion of the topic presented? Are they frustrated, asleep, chatting with each other or still focusing on the concepts explained? Who is participating, pondering a difficult matter, or taking notes during the session? all these aspects are possibly noticeable in classical or traditional teaching/learning environment but not in online mode [32].

Based on these arguments, the educators are facing new challenges with online mode that could urge a dire need to motivate students to stay focused, participate and join the herd of all students in virtual class. In addition, it could possibly create inner positive or negative feelings about the new situation. In other words, to maintain an appropriate control of the class's community, the educators find it more difficult to practice during or, at least, in the early phases of applying online teaching/lecturing.

\subsection{Bahrain as the Context of the Study}

The rapid infection of the coronavirus rendered the epidemic to become a pandemic that spread out to other countries. Iran, Italy and Spain were the most infected in the early stages of the pandemic and were considered epicenter in their regions. The GCC countries were susceptible to this outbreak as they are nearby Iran, which responded by closing their borders to flights from infection epicenters in an attempt to flatten the infection curve. Bahrain, as a member of the GCC, applied a bundle of emergency measures to protect citizens and residents. These measures included the cancellation of many activities (e.g., social, entertainment, academic and sports), the closure of schools, HE institutions and all training and community centers [17] and the transformation of the activities of many businesses and government sectors into online. These measures had proved to be effective during the influenza pandemic in the US in 1918 to curb the infection by cancelation of gatherings and closure of educational institutions [6]. After the suspension of educational institutions in Bahrain on 25 February 2020 [25], universities started to use virtual classes by means of Microsoft Teams, Blackboard and other tools to facilitate access to instructional content that helped the students as well as the educators to continue the pedagogical process, communicate and live broadcast [17].

Overall, the people of Bahrain followed two trends in accordance with the hard decisions imposed under full lockdown, social distancing and working from home Makrakis and Kostoulas-Makrakis [33] defined two types of these measures. First is the top-down trend, in which the government enforcement of measures for the common good, considered an external locus of control. Secondly, the down-top trend in which the individuals chose to adhere to social distancing as driven by personal will, ethics and based on the cognition of the consequences of not following the safety instructions announced locally by their government or globally by the World Health Organization (WHO). In fact, the down-top trend represents the individual responsibility and the top-down trend represent the collective responsibility or co-responsibility. In general, HE institutes largely followed the second trend, 
strengthened by the government's top-down measures. In fact, the HE's top-management, the educators and the different stakeholders understood the risks of being on-campus to continue the educational process. The risk of gathering evoked several meetings inside the $\mathrm{HE}$ institutions as well as with government entities in Bahrain and working from home was decided as the only plausible available options. Therefore, the government measures resulted in the individual responsibility and the collective responsibility.

During hardships, adversities and catastrophic events such as the COVID-19 crisis, solidarity plays a vital role in showing respect and reducing stigmatization. It is not only a matter of bringing people together occasionally, but also creating a healthy and supportive environment to ensure sustainable development. In the educational environment, this sense of solidarity has a favorable outcome as it is the co-responsibility of all stakeholders with a common objective, i.e., the sustainability of the educational process. Therefore, the role of university management of Bahraini universities was crucial during the pandemic, enabling the teaching and academic staff to continue working in a supportive environment.

\subsection{Innovation and Open Education during the COVID-19 Era}

In general, the starting point of innovation is an idea, need, or opportunity. The innovation is then introduced to the market to meet the expectations of the beneficiary [34]. Innovative approaches are crucial in the educational process and to obtain it, there should be specific goals to achieve it. In principle, innovations can be said to be ideas, actions, or objectives that are perceived to be new for the educational market (the adopters) [34]. Hence, having this in mind, the innovation outcome can be distinctive from its former status quo and considered new way or method to the educational market. Another interesting definition of innovation by scholars [35] state that new services, strategies, procedures, business or organizational structure, or business models denote the term innovation and this definition resulted from the emergence of innovative systems' approach that rooted during the 1990s. Additionally, one of the important phase of innovation development is the problem or need that is followed by research, development, commercialization, then the diffusion of the innovation and, finally, the results with its consequences [34].

Moreover, innovation not only creates new products, procedures, or processes, but also adds improvements to current practices or methods and opens or adds new directions, ideas, processes, or approaches. In the educational setting, in order to move the entity forward and be innovative, the leadership has to evaluate the capacity of their staff and consider finding or changing into new ways of delivering, imparting, or creating the requisite knowledge, skills or experience to ensure its alliance with the market trend. This would result in an increase of profitability, rivalry and enhancement [34] that would reflect on the innovation's beneficiary or the outsourcing entity. Therefore, the success of innovation in education is contingent on the integration between the industry and educational entities as well as learning the success stories and models from the industrial sector and adopting them in the educational system.

COVID-19 illustrate the necessity of collaborating with all stakeholders to build innovative learning/teaching environments that possess open resources and practices, with diverse materials that cover different cultures, languages and disciplines [36]. Different stakeholders, such as educators, students and decision makers, need to expand educational paths: open education can be a vital player in this regard. Further, open education supports the teaching/learning processes that can help the student to continue education with open platforms and the educator to create, adapt, improve and change the way of syllabus delivery. Generally speaking, different resources such as text, tools, technologies, data and practices in open innovation education require collaboration and commitment to democratize knowledge to be accessible and supportive to everyone and offer the social appropriation of knowledge [36]. 
In open education linked with innovation, it is necessary to align the practices of educators with educational innovation in order to be more creative and adaptive to the changing nature of market trends. There are two types of open innovation, in-bound and out-bound [37]. In in-bound innovation, the scientific and technical competences between any entity and an external organization/entity is established in order to enhance, improve, or foster the innovative performance of the entity seeking it. In other words, it is the innovation of external entities that is brought and employed into an inside entity/organization seeking it. This is usually a practical solution in times of adversity or risky situations, such that of the coronavirus pandemic, adopting new or advanced practices, processes, tools and resources with proven implementation and success stories. This is applicable to those universities that were not ready for the sudden shift towards online education; they can adopt ready-made solutions in order to continue the pedagogical process without disruption. On the other hand, out-bound open innovation is the establishment and management of knowledge that is exploited for external beneficiaries outside the entity itself. This is true for universities that have invested heavily in the production of educational systems, resources, or tools inside their premises and gained the desired outcomes. Therefore, it is plausible and acceptable to fully exploit their experience with external educational or organizational entities in order to obtain financial resources for running their innovative projects when they outsource their experience, tools, procedures, or resources.

Educators are the building blocks in the success or failure of providing skilled workers with competences to build the future of industry with innovative solutions [34]. If HE institutions are unable to meet industry's demand for talented workers, inevitably they will lose favor with manufacturers, their revenue for more students' enrolments and eventually companies and people would leave to a more promising location. Therefore, building the capacity of the educators and exposing them to innovative programs to hone their existing teaching and academic skills or create new skills can effectively increase their self-efficacy, which is essential to cope with the current challenges of online education during COVID-19.

In difficult times such as the emergent COVID-19 pandemic, there is a need to change or improve the transformation of vision and actions in educational systems by improving the structure, the actors and management of resources [36]. This should happen in a constant manner to cope with the emergent situations and turbulent environments. Working with open resources, open platforms and collaborative practices can enhance the education process [36], especially as the repercussions of the current pandemic uncovered the critical gaps needing further research to identify the causes, consequences and the adaptive solutions. Research should also pay more attention to good practice with new processes, services, products and knowledge which enhance innovation in educational environments and are eventually expected to produce innovative improvements.

The concept of open innovation has gained popularity during COVID-19. According to [38] "open innovation is particularly relevant now because many firms required to implement open innovation to survive and grow in the competitive environment". Many educational institutions have developed and implemented innovative approaches to teaching, learning and assessment. According to [34], educational institutions must understand the systematic nature of innovation, the complexities of the system and the dynamic nature of the innovation system elements. The researcher [34] explained how innovation dimensions and types must be applied and how to define and implement innovation process flow. In another article, [36] reviewed recent publications on open education, the author stressing the need to focus research on good practices that address the results of new processes, products, services and knowledge that support innovation in educational teaching/learning environments and are expected to make the anticipated change and improvements. 


\subsection{Hypothesis Development and Research Model}

\subsubsection{Academic Staff Task Performance (TSK_PER)}

Performance is a complex topic with hidden structure and abstract notions that make it difficult to give a specific definition; it reflects different dimensions, employed in a variety of contexts and with different usage $[39,40]$.

Performance may denote achievement, accomplishment, the outcome of an action, behavior, the task done or the use of a method, instrument or abstract concept. In the literature, the definitions vary depending on the usage and context of study. For example, task performance can mean the main work tasks (i.e., basic or technical) that play a central role and should be performed according to the competence of the worker [40]. It is also defined as measuring the effectiveness of a predetermined standard, norm or goal in a systematic way [41]. However, some scholars divide performance into three dimensions: contextual performance, counterproductive work behavior and task performance [39]. Others have added further dimensions such as adaptive performance, interpersonal performance and organizational performance [40]. To narrow the scope of this study, the current research focuses on the task performance of academic staff in carrying out different duties, tasks and activities that are related to their academic being as a demand or responsibility.

Other studies have defined task performance as the individual's proficiency in achieving tasks directly related to their job $[39,42,43]$. Another recent definition of job (i.e., task) performance is, "behaviors related to meeting expected, identified or formal role requirements of organization members" [40]. This definition has two components, i.e., human behavior either as an individual or group and the timeframe of required to accomplish the task [40]. Therefore, task performance in the context of this study refers to performing the academic and teaching tasks requested by the institution, professionally, optimally and on-time; for example, the transformation of the pedagogical process from the conventional face-to-face method to blended or online education through digitized materials, methods, or equipment, as a consequence of the COVID-19 pandemic.

It is plausible and widely accepted that one of the main pillars of the success of any organization is its employees' performance of their tasks, according to the schedule for completing implementation, organizational policy, or a contract signed with other internal or external entities. Achieving high performance is positively reflected on the success, achievements and revenue for the affiliated entity as well as the staff themselves [44].

Individual capabilities are a means of achieving the tasks assigned or duties required in a specific situation. For instance, if one has the correct skills, knowledge, or experience to carry out a specific action, it is more likely to perform well under controlled circumstances. Furthermore, negative and positive feelings or emotions can strongly affect one's performance even in the presence of the skills and capabilities to perform well in a specific situation or environment. However, the unexpected and uncontrollable repercussions of COVID-19 tried the performance of the academic staff. That is, the educational process has to continue and at the same time the closure of HE institutions and the lockdown placed an extra burden on both the institution and staff. With this justification, the researcher assumes a logical linkage between task performance, on the one hand and negative and positive feelings as well as self-efficacy (i.e., his/her capability) of the teaching and academic staff, on the other. Some of these emerging feelings, whether positive or negative, can be related to the attitude of management, the regulations and the working environment in the organization, as well as to the COVID-19 pandemic.

\subsubsection{Effect of Negative Feelings (N_Feel) on Task Performance}

The sudden COVID-19 outbreak affected normal life on the macro-level (i.e., organizational sector) and micro-level (i.e., individual). On the larger scale, this extended to many areas touching our essential and daily needs, such as government activities, tourism, business deals and production, transportation, social activities, industry, healthcare procedures and education. At the micro-level, COVID-19 resulted in negative feelings and emotions such as anxiety, fear, stress, exhaustion, frustration and disappointment in the majority 
of the workforce globally. One of the important pillars of society, academic and teaching staff, were severely affected by these emerging and sudden changes. These negative feelings can affect the productivity of employees in general-and this important sector of the community in particular - the motivation to work harder and mental health [45-48].

In the context of this research, the effect of negative feelings on the performance of academic and teaching staff in the era pandemic is manifest as the sense of fear, stress, depression, anxiety, boredom, disappointment, uncertainty, exhaustion, disappointment, or frustration perceived, affected or practiced and leading to degradation of their productivity (i.e., task performance), motivation, physical and mental wellbeing. A large body of literature has stressed the negative consequences of COVID-19 on the individuals' wellbeing [45-48], affecting their achievements, productivity and adherence to the HE institutions' performance policy. Negative emotions can also adversely affect intrinsic and extrinsic motivation, the effortful processing of information and, consequently performance [49]. For example, boredom and hopelessness as negative emotions are found to be negatively correlated with performance [50]. In addition, anger and anxiety are argued to create irrelevant task thinking and reduce intrinsic motivation that weakens productivity or performance, whereas boredom is felt when the demand is high and capabilities are correspondingly low [50]. Exhaustion, stress, frustration or feeling overwhelmed are arguably induced by negative events such as excessive work, with new and difficult tools within a limited time (e.g., transforming lessons into digital format and following up students and the administration). On the other hand, anxiety, anger, doubt and disappointment are expected to be induced by the negative view of the future, losing a job, uncertainty of the duration of the infection or inability to change the dominant, uncontrollable, unavoidable situation such as the infection of COVID-19.

Reports from different countries agree on common symptoms exhibited during the pandemic, such as depression, stress, anxiety and fear $[46,51,52]$. These negative feelings may occur as a result of the lockdown and working from home, social isolation, caring for children and parents, preparation of job tasks in digital format and virtual communication. This sudden change in the course of normal life has encouraged researchers to explore the short-term and long-term consequences to both, the working individual and the organization, as affecting task performance. This includes a call for research into the psychological influence of COVID-19 [45,52]. Even at the current early stage of the infection, there are clues to drawing a roadmap to overcome these situations in order to avoid the negative consequences on individuals and organizations. For educators, this phenomenon affects not only themselves, but also the future of our children's education. Hence, the following hypothesis is assumed:

Hypothesis 1 (H1). During COVID-19, negative feelings are assumed to have a negatively statistically significant relationship with task performance.

\subsubsection{Effect of Positive Feelings (P_Feel) on Task Performance}

In the context of the current research, P_Feel can be interpreted as the sense-felt by academic and teaching staff-of high morale, management and colleagues' support, social interaction with others virtually, being energetic while practicing sport at home and being positive about good news such as recovery from COVID-19, which could impact their productivity or motivation to do their tasks efficiently or as expected by their employer.

The effect of emotions on the achievements, productivity or performance in the academic context is apparent. Pekrun [53] argues that positive emotions produce positive outcomes, whereas negative emotions such as anxiety or dissatisfaction might be ambivalent [53]. The author also claims that the emotions and achievements or good performance have a reciprocal causation [53]. That is, the effect of positive emotions results in better motivation that reflects better performance, future optimism, positive motivation and higher expectations of future success. Similarly, in the context of the study, the research assumes that the positive feelings perceived by the academic and teaching staff can be 
positively correlated with the tasks assigned to them, creating better performance in the virtual classes or in the preparation for the transformation of conventional methods to online education.

Positive feelings can be a crucial motivator in the performance of tasks and duties, enhancing problem-solving strategies and adjustment to coping with crises. Positive emotions are assumed to promote both intrinsic and extrinsic motivation, help in learning strategies and support self-regulation, thus affecting performance [49]. Individuals with positive emotions are better at dealing with changing and difficult situations than those with negative emotions and a pessimistic view of life $[54,55]$. This positivity leads to better productivity and higher performance.

Management support is also crucial to productivity, motivations and achievements of the staff working in these difficult times especially with the increasing burden inside and outside HE institutions. Inside, can be referred to caring for family during the lockdown in terms of providing the essentials to survive as well as teaching children and supporting spouses physically and mentally. Outside, the pandemic has increased responsibility in all pedagogical activities with the transformation of conventional courses into digital form. Therefore, high morale is essential and the management of the educational institutions should support it. When this support is felt by the academic and teaching staff, it is more likely to enhance and boost their performance. to do all tasks professionally-as before-happily and as expected by the management. This view is supported by [39], that management support affects the performance of employees, boosting morale and thus the motivation, commitment and positivity of employees.

Optimism is one of the key elements of being positive in order to make one adjust to a new and difficult situation or hardship. In other words, it is a handy tool to reduce stress [54]. Optimism, which can infer the positive feelings, has a positive influence on longterm psychological and physiological wellbeing [55]. A supportive network-inside from management or colleagues or outside the workplace from family members or friends-also generates better performance, job satisfaction and psychological wellbeing [56]. In other words, this positivity felt by employees drives them to devote a large portion of their cognitive capacity and time to tasks related to their organization [56]; hence, their task performance is improved.

Social media has become a valuable and dominant communication tool during the pandemic lockdown. Chatting (e.g., with friends, colleagues and relatives), working remotely, entertaining, communicating and obtaining positive news updates play a role in the virtual context of COVID-19. In other words, when positive news of the recovery increases or when chatting with colleagues about handling the many problems faced during the transformation of the courses, positive feelings are engendered in the teaching/academic staff. In addition, being at home may bring some positive feelings. The boredom of sitting at home day and night can be counterbalanced by chatting with children or spouse, breaking the hold of the negative feelings. Exchanging ideas, concerns and hopes inside the family can create a new atmosphere for positive feelings and relationship. Although being at home has created some negative consequences on the relationship between husband and spouse especially the working ones, the general view is that being passionate, supportive and caring create positive atmosphere when social isolation took place. Engaging in sport, even inside the house, can also promote positivity.

Overall, then, positive feelings (i.e., being cheerful, in good mood, joyful, feel relief, socially connected and maintaining the morale) can lead to a more balanced and positive attitude, reflected in the motivation and eagerness to perform well during the COVID-19 stressful times. Consequently, the following hypothesis is proposed:

Hypothesis 2 (H2). During COVID-19, positive feelings are assumed to have a positively statistically significant correlation with task performance. 


\subsubsection{Effect of Self-Efficacy (SEF) on Task Performance, Negative and Positive Feelings}

Self-efficacy, with roots in the social cognitive theory (SCT) [57], is defined as the belief and judgment of one's capabilities and competences in doing an action to achieve specific types of performance and manage prospective situations [58,59]. Consistent with this view, self-efficacy is referred to "an individual's convictions (or confidence) about his or her abilities to mobilize the motivation, cognitive resources and courses of action needed to successfully execute a specific task within a given context." [60]. Within the context of the present research, self-efficacy is seen as the academic/teaching staff's belief in their capabilities, skills, patience, intellect, indomitable will and competences to organize or execute the assigned tasks to deliver the course's contents to students, achieve academic goals and perform well and on a timely basis during the COVID-19 pandemic, utilizing digital methods. In principle, online teaching requires the tutor/educator to possess or develop more skills, such as using a variety of technology devices and applications, building social skills for the online community, having creative teaching skills alongside developing a personal teaching style in the new medium [61].

The effect of self-efficacy on performance is evident and related to one's skills to fulfill a specific task in a certain context while adapting to changes in the environment [56]. In addition, those who possess a high level of self-efficacy are more likely to choose challenging situations with extended motivations and efforts in order to succeed in achieving their objectives, especially when obstacles or complex situations lie in their way $[56,62]$.

In is widely accepted that self-efficacy has a crucial role and is a primary influencer on one's performance of a certain task. It also has an impact on the prediction of motivation and performance $[59,63]$. Conversely, [64] claimed that a low level of self-efficacy can lead to avoidance behavior. In general, people participate in specific activities or tasks when they have the feeling of self-efficacy and trust their competency in performing a specific task. That is, if one has this positive sense and trust in his/her capabilities, this would lead to an increase in their positivity in performing a specific task.

On the other hand, a low level of self-efficacy may create or increase a sense of negativity in performing a certain task or action. In other words, being less inspired, as a result of negative feeling, would decrease the commitment to reach the intended goals and, therefore, reduce performance. Low self-efficacy may also lead to avoidance behavior, especially in threatening situations where one expects the worst as a consequence of lacking trust on his/her own capabilities. [57]. On the other hand, possessing a high level of self-efficacy make one show more persistence, devotion and commitment under complicated conditions and becoming involved in activities based on judgment of their capabilities in handling these situations, rather than sidestepping them [57,64]. Therefore, the current research proposes the following three hypotheses:

Hypothesis 3 (H3). Self-efficacy is expected to demonstrate a significantly positive statistical relationship with task performance.

Hypothesis 4 (H4). Self-efficacy is expected to reduce the negative feelings to better achieve the tasks assigned and raise the performance of academic and teaching staff during COVID-19.

Hypothesis 5 (H5). Self-efficacy is expected to increase positive feelings to better achieve the tasks assigned and raise the performance of academic and teaching staff during COVID-19.

Given these formulated hypotheses, Figure 1 depicts their relationships in a conceptual framework. 


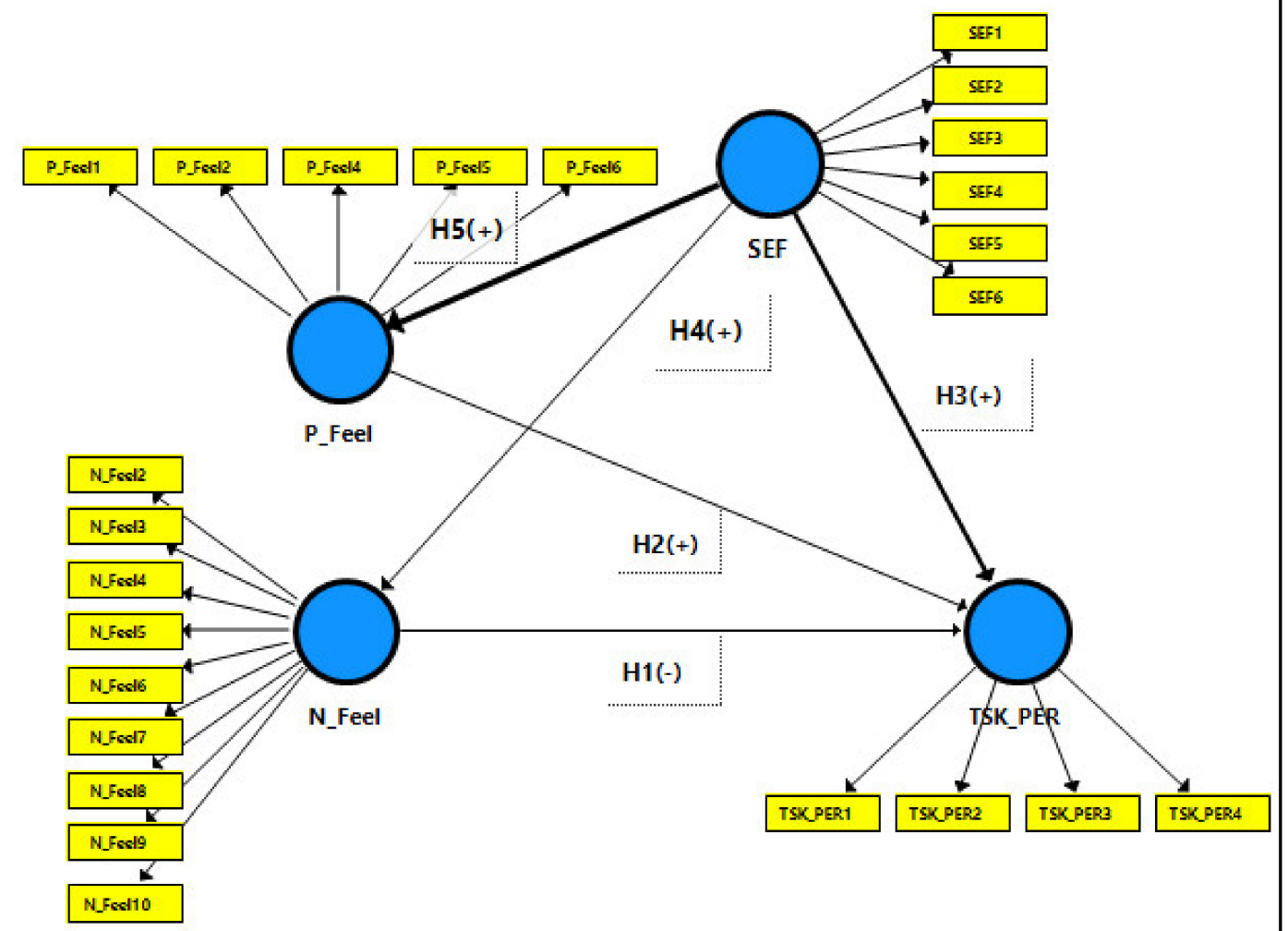

Figure 1. The research's conceptual framework.

\subsection{Artificial Neural Network}

\subsubsection{Artificial Neural Network (ANN) Definition and Introduction}

The original idea of neural networks came from the human brain, which comprises billions of neurons in the form of fully connected networks [65]. Artificial neural networks (ANN) can be defined as a parallel distributed system consisting of processing units that can store experimental knowledge for retrieval [66]. ANN is, thus, a smart system that resembles human-like thinking [67] through learning [68] and training and has the ability to obtain knowledge, store it by synaptic weights and recall it for decision making in similar environments, situations, or events. It has robust tools that can give better accuracy than conventional statistical analytical methods [69]. The neural network analysis approach has been implemented in various fields, including m-commerce [70,71], e-business [72], banking [65] and behavioral, acceptance and adoption studies [67-69,73,74]. However, greater breadth and depth through its use in combination with PLS-SEM is still at an early stage in related studies in social science, human-computer interaction, human behavior and individual performance during COVID-19.

\subsubsection{Architecture}

In simple terms, ANN is composed of three main layers: the input layer (where the features or independent variables are connected to it from one side and to the directly connected hidden layer from the other side); the hidden layer(s) (i.e., where the black box resides with the neurons and the activation algorithm); and lastly, the output layer (i.e., where the dependent variable or the final outcome resides). More importantly, the activation function inside the network is an essential element of neural networks, which pushes the weighted sums from one layer to the next succeeding layer. It has to be kept in mind to select the proper and suitable activation function that is aligned with the output variable. If we have a binary output, the sigmoid function is selected. If the model has several classes (categorical output), the suitable output function is SoftMax algorithm; 
otherwise, the identity function is selected to suit the continuous variable (i.e., scaled dependent variable) of the output. This general rule of thumb has been neglected in some previous works, failing to distinguish between the different outputs, i.e., binary, categorical with multiple labels of classes, or continuous variable output. Figure 2 depicts a simple neural network architecture.

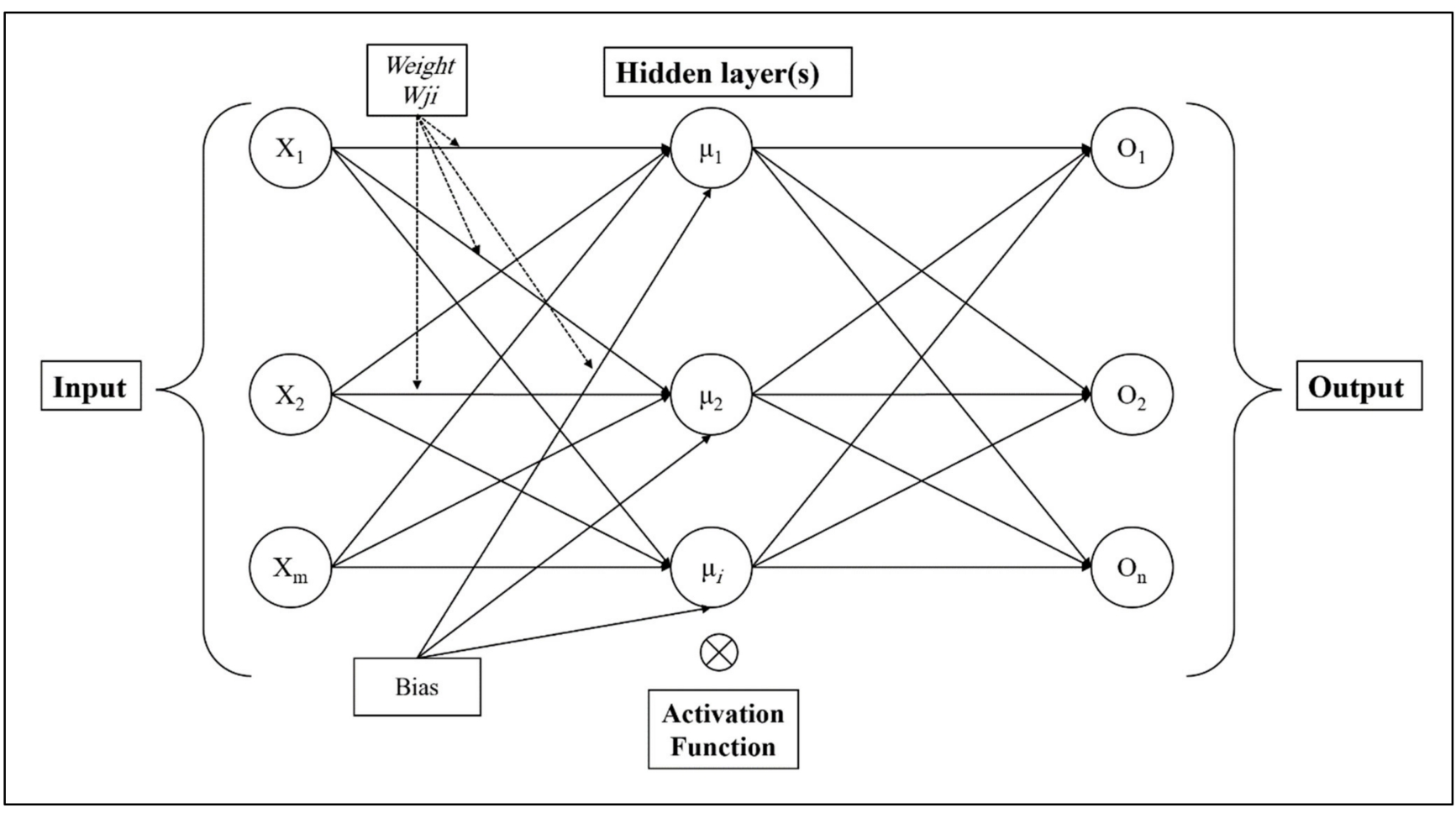

Figure 2. Simple architecture of MLP-ANN.

\subsubsection{Criteria Defining the Number of Neurons and Layers}

The last important design element is the number of hidden layers and neurons, which can be identified by the user or set automatically. However, for a simple model, such as the current model, the one-layer design architecture (for the hidden layer) is selected as no complexity resides in the model and is sufficient to present any continuous variable. Pertaining to the number of neurons in the three layers (input, hidden and output layers) we can summarize it as follows. The number of input layers corresponds to the input attributes/features/variables. In this research, the input variables are SEF, N_Feel and N_Feel. The output layers depend on the number of output dependent variables, which is one in this research (i.e., TSK_PER). However, there is no precise way to identify the appropriate number of neurons [75]. In fact, it depends on several aspects such as the sample size, the number of hidden layers, the complexity of the model and the activation function [76], as they affect the processing of the training and the prediction accuracy [76]. In general, the number of neurons is between the number of input and output neurons [76], although it can be adjusted on a trial basis. Based on the challenge in identifying the number of neurons, the most common way in literature is to select the ten-fold approach; therefore, this research adopted 10 neurons or nodes in the postulated model. In addition, it should be noted that the more neurons and layers, the slower the processing power of the computer.

The system of connected neural networks can handle complex models and predict the outcome more efficiently than traditional methods in linear and structural relationship evaluation of the indicators (or the measured variables/items/attributes) and their related latent constructs [77]. There are different types of ANN: multi-layer perceptron, recurrent, 
feedforward and radial basis function [68,69]. Multi-layer perceptron (MLP), adopted in this study, has the advantages and disadvantages summarized as follows [78]:

- Non-linearity: Neural networks possess a non-linear attribute and, therefore, support non-linearity, which is an important aspect especially if the relationship between input and output is non-linear.

- Learning to adapt to a new situation or returned feedback from the process of backward-feed propagation. This learning curve does not require user intervention and makes the MLP preferable.

- Input-output mapping requires supervised training that makes the network adapt the coefficient's weights in the input layer as a result of the backward-feed from the output layer to minimize errors. To explain, when a batch of attributes are forwarded to the network from the training set, there is desired and preferred output and the actual output. The weighted coefficients are adapted to reduce the difference between what is desirable and the actual output. This flexible and continuous mechanism on the training set of the data aims to converge in order to reach a stable state.

- Robustness: Unlike PLS-SEM, the performance of the neural network degrades when there is increasing noise in the network.

Despite its advantages, MLP exhibits slow convergence with the sigmoid function and results (predictions) cannot be interpreted in a reliable way. However, in line with previous work [68-70,76,79,80], this study employs MLP with feed-forward and backpropagation mechanisms to identify the relative importance of latent constructs that affect the dependent construct of task performance. Additionally, it compares the results obtained from PLS-SEM with those of the ANN analysis. A last important aspect in the design and architecture of ANN models is to divide the dataset into a training set and a test set. The training allows the system to calculate and obtain insights into the data, learn from it and produce the final outcome that will be used to predict the model from the test set. The data in this research were divided into $90 \%$ as a training set and $10 \%$ as the test set $[79,81]$.

\subsection{Differences and Complementarity in PLS-SEM and ANN Implementation}

ANN has been found to outperform traditional compensatory models [68,74] such as logistic, multiple and discriminant regression analyses, in that distribution assumptions (e.g., normality, linearity or homoscedasticity) are not an issue with ANN [66,76], as well as the linearity or non-linearity nature of the dataset obtained from the model evaluated [66]. Another drawback of SEM is its inability to tolerate noisy data [66,73]. Despite these facts, ANN is unable to evaluate structural relationships (i.e., hypothesis testing) between different latent constructs or to give estimations of $p$ values and coefficients of the paths, such as in PLS-SEM [77]. More importantly, the dependent variable(s) can have both linear and non-linear effects in the relationships of the model which can overgeneralize the results if only SEM is used and neglecting the non-linear effect that can be predicted by ANN. Taking these points into consideration, the research adopts a two-stage analysis using an ANN(MLP)-SEM(PLS) approach, as they are complementary. In addition, the feedforward back propagation MLP is the most widely accepted approach [66,68,76,77].

\section{Research Methodology}

The methodology applied in the current study follows the popular two-step approach $[68-70,76,79,80]$ to validate and evaluate the model and hypotheses. Before applying these two approaches, a rigorous analysis of the items was conducted, such as the normality, linearity and multi-collinearity assumptions, to ensure the items are suitable for the next analyses. After the initial evaluation of the items, PLS-SEM procedures was applied, starting with the measurement evaluation followed by the structural evaluation of the hypotheses. Next, the only significant relationships revealed from PLS-SEM analysis were tested using MLP-ANN evaluation. However, before proceeding to the MLP-ANN analyses, the model was decomposed into three sub-models, as in earlier studies [75,76], to enable correct analysis of the model as a whole and to ensure that no portion of the 
proposed conceptual model is neglected. The dataset was divided into a training set $(90 \%$ of the data) and a test set $(10 \%)$. Running the training set enables the system to learn and then to predict the output based on the training cycles. After obtaining the results from MLP-ANN analysis, the significance of the predicters was evaluated and the importance of each one identified and compared with the results obtained from PLS-SEM.

\subsection{Development of Survey Measurement Items}

Three predictors (i.e., self-efficacy, negative and positive feeling) were included to study their impact on the dependent variable (i.e., task performance). The role of selfefficacy on the positive and negative feelings was further explored. Twenty valid items were employed in a close-ended survey instrument to measure the three independent latent constructs and four items for the dependent latent construct. The survey was divided into two sections, i.e., the demographics and the latent construct items.

Five TSK_PER items were adapted from [43], two SEF developed questions from [82,83] and four items were author-developed to suit the nature of the study: (1) technical skills, background and knowledge; (2) patience; (3) intellectual capabilities; (4) strong will to understand, learn, practice and use the digital methods and to deliver the digital content of the courses. The positive feelings experienced during the pandemic, P_Feel, were represented by six items and negative feelings, N_Feel, by 10 items, as independent latent constructs. These items were author-developed to suite the coronavirus pandemic context based on the alluded feelings in concurrent literature. A Likert scale ranging from 1 (strongly disagree) to 5 (strongly agree) was employed to measure responses to the statements. The survey questions can be found in Table A1 in Appendix A.

\subsection{Survey Deployment and Analytical Tools}

After the initial development of the survey, it was evaluated by four university professors; amendments were made based on their comments and recommendations. A pre-test was conducted with ten respondents of the same targeted population to ensure its suitability and appropriateness. In the last phase, the final version of the survey was distributed to target academic and teaching staff in private and public universities in Bahrain. Different analytical software tools were used for the evaluation process: Microsoft Excel (for the computation of different results), SPSS version 24 (for the initial phase of measurement items and multivariate assumptions evaluation) and the PLS_SEM analytical tool of Smart PLS M3 [84] (for the evaluation of the model, i.e., the measurement and structural models).

\subsection{Population, Sample and Sampling Procedures}

The population consists of the staff at the HE sector in Bahrain. However, the sample frame (the target sample) is the academic and teaching staff of public and private HE institutions. So, the unit of sampling is these staff working during the COVID-19 lockdown. A quantitative survey instrument was developed and distributed using non-probability purposive sampling and snow-ball techniques to collect data. Purposive sampling, of those who are suitable for providing the information sought by the researchers [85], is suitable as the sample is relatively small and generalizability is not drawn [85].

The deployment of the questionnaire was through the online Google Forms website; the link was distributed through WhatsApp or email addresses. Potential respondents received reminders every three days and at weekends. After collecting the data, a screening phase was conducted to eliminate incomplete responses.

\subsection{Sample Size}

Using $G^{*}$ power software [86] to define the minimum sample size, the following parameters were set: an alpha error probability (0.05), power of 0.80 and medium effect size (0.15) are recommended in literature [87]. The minimum sample size was 77; 83 the valid responses were collected, a response rate of $94.3 \%$, as five incomplete responses were eliminated. 
4. Data Analysis, Results and Discussion

4.1. Respondents' Profile and Characteristics

Results revealed a $51.81 \%$ of respondents were female and $48.19 \%$ male, as shown in Figure 3.

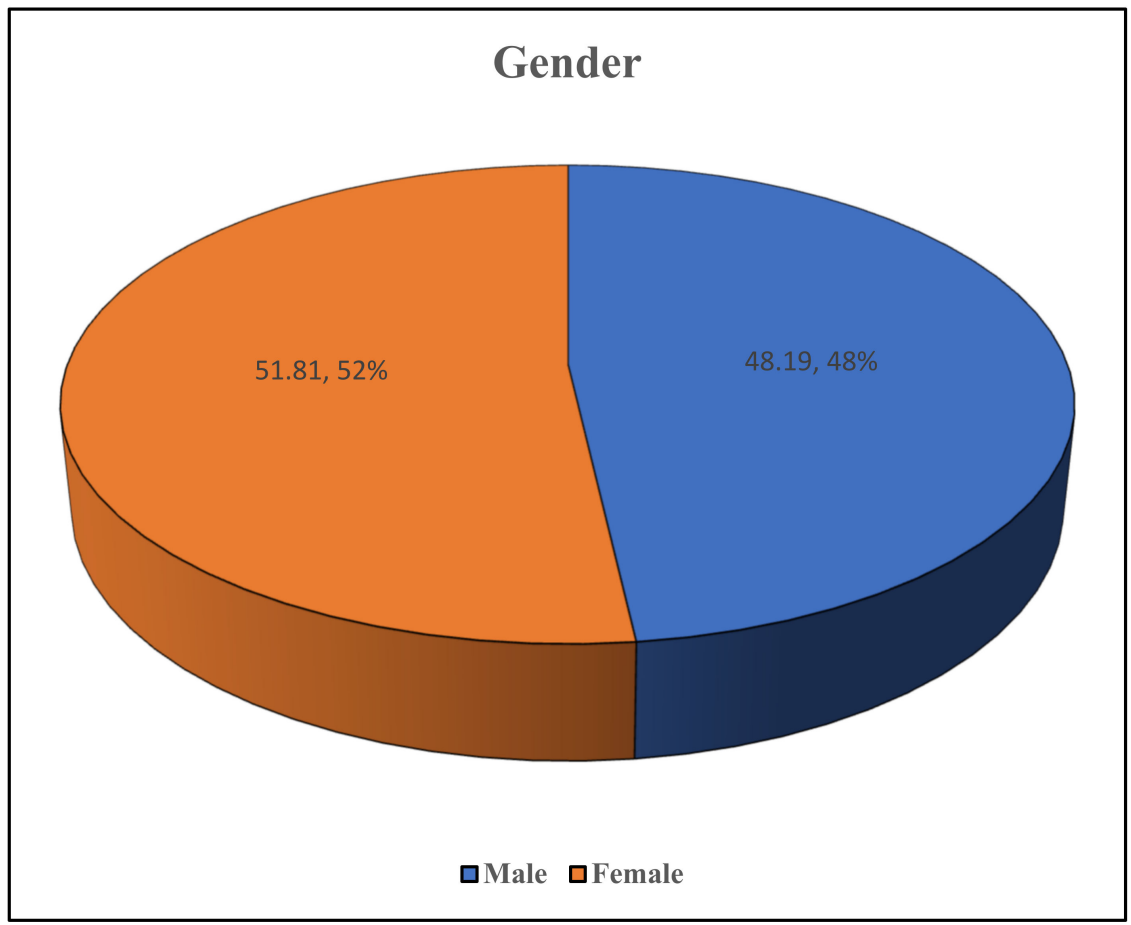

Figure 3. Gender distribution.

Figure 4 depicts distribution by age, with Group1 dominant, followed by Group3.

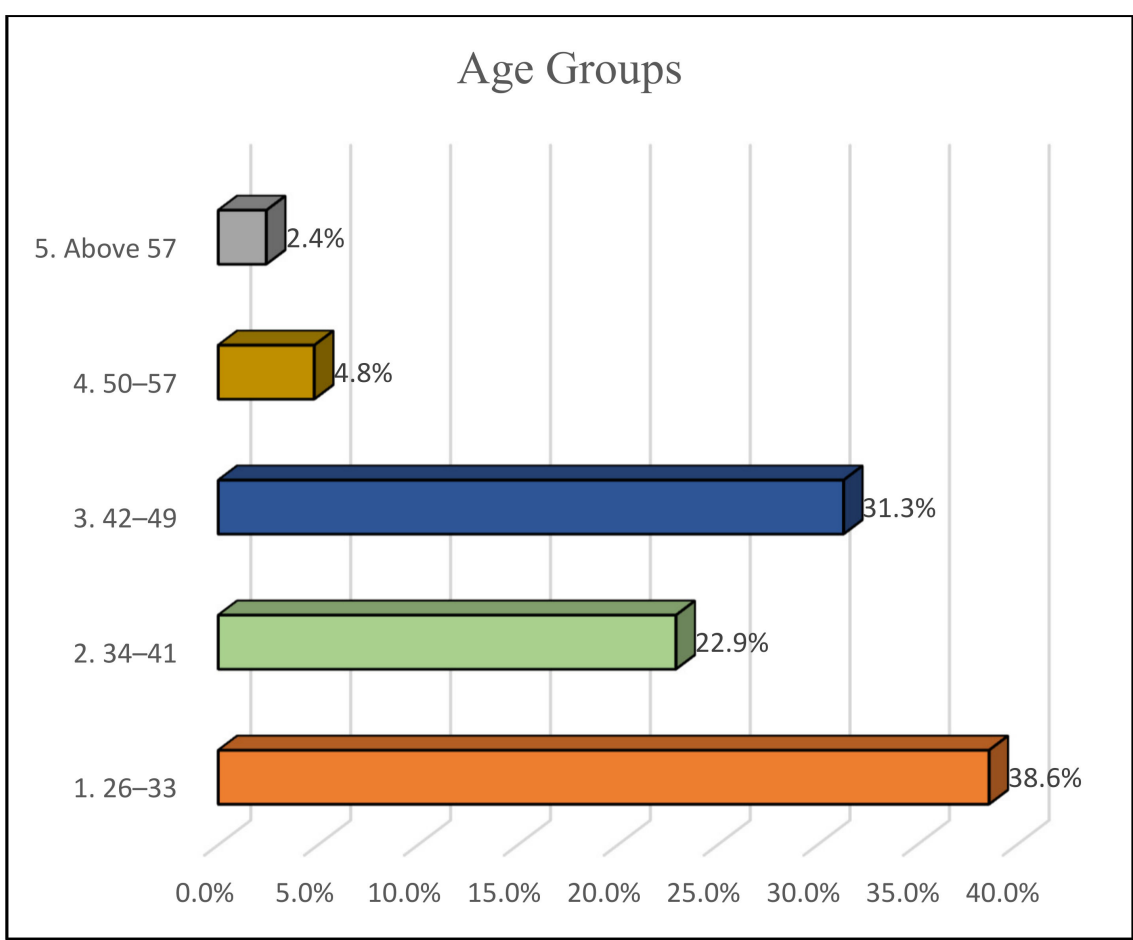

Figure 4. Age Distribution Groups. 
Pertaining to the educational level, unsurprisingly almost half held a doctoral degree. With regard to experience, a quarter had experience of less than 3 years $(25.3 \%)$ followed by the group with more than 17 years $(24.1 \%)$. The lowest percentage, $13.3 \%$, was for those having experience between 13-17 years. See Table 1.

Table 1. Respondents' demographics of experience and academic degree.

\begin{tabular}{llll}
\hline Attribute & Std. Deviation & Freq & Percent $\%$ \\
\hline Experience & 1.52 & & \\
1. Less than 3 years & & 21 & 25.3 \\
2. 3-7 years & 15 & 18.1 \\
3. 8-12 years & 16 & 19.3 \\
4. 13-17 years & 11 & 13.3 \\
5. More than 17 years & & 20 & 24.1 \\
Total & 83 & 100 \\
Academic Degree & 1.15 & & \\
1. Diploma & & 11 & 13.3 \\
2. Bachelors' Degree & & 8 & 9.6 \\
3. Master's Degree & & 18 & 21.7 \\
4. Ph.D. Degree & & 41 & 49.4 \\
5. Post Doctorate & & 5 & 6 \\
Total & 83 & 100 \\
\hline
\end{tabular}

\subsection{Indicators from Preliminary Analysis Phase}

In this phase, common method variance (CMV) was evaluated by applying Harman's single factor (unrotated) test in which the unrotated first factor should account for less than $50 \%$ of the total variance explained by all other factors [88]. The variance obtained was $39.74 \%$, which is less than $50 \%$ of the total variance explained; therefore, no issues of CMV popped up.

The dimension reduction analysis—exploratory factor analysis (EFA) - was employed to examine the linkage between the items and its correspondent construct (i.e., variable) as well as to remove the items with weaker loadings. Principal component analysis (PCA) with varimax rotation was employed to identify the number of factors and related items. To judge the number of factors to retain or remove, a recommended cut-off eigenvalue greater than 1 indicates those factors to be retained. The percentage of variance was also evaluated. The eigenvalues were greater than 1, but two items (N_Feel1 and P_Feel3) were removed: as their outer loadings were weak, 0.478 and 0.554 , respectively. The detailed statistics are depicted in Table 2.

Table 2. Initial factor analyses and dimensionality reduction.

\begin{tabular}{|c|c|c|c|c|c|c|c|c|}
\hline \multirow{2}{*}{ Construct } & \multirow{2}{*}{ Mean } & \multirow{2}{*}{ Sth. Deviation } & \multirow{2}{*}{ Variance } & \multirow{2}{*}{ Items } & \multicolumn{4}{|c|}{ Factor Loadings } \\
\hline & & & & & F1 & F2 & F3 & F4 \\
\hline \multirow[t]{6}{*}{ Self-efficacy } & 3.23 & 4.68 & 21.93 & SEF1 & 0.87 & & & \\
\hline & & & & SEF2 & 0.82 & & & \\
\hline & & & & SEF3 & 0.87 & & & \\
\hline & & & & SEF4 & 0.84 & & & \\
\hline & & & & SEF5 & 0.79 & & & \\
\hline & & & & SEF6 & 0.84 & & & \\
\hline \multirow[t]{9}{*}{ Negative Feelings } & 23.83 & 7.37 & 54.35 & N_Feel2 & & 0.65 & & \\
\hline & & & & N_Feel3 & & 0.79 & & \\
\hline & & & & N_Feel4 & & 0.84 & & \\
\hline & & & & N_Feel5 & & 0.74 & & \\
\hline & & & & N_Feel6 & & 0.77 & & \\
\hline & & & & N_Feel7 & & 0.73 & & \\
\hline & & & & N_Feel8 & & 0.81 & & \\
\hline & & & & N_Feel9 & & 0.71 & & \\
\hline & & & & N_Feel10 & & 0.69 & & \\
\hline
\end{tabular}


Table 2. Cont.

\begin{tabular}{|c|c|c|c|c|c|c|c|c|}
\hline \multirow{2}{*}{ Construct } & \multirow{2}{*}{ Mean } & \multirow{2}{*}{ Sth. Deviation } & \multirow{2}{*}{ Variance } & \multirow{2}{*}{ Items } & \multicolumn{4}{|c|}{ Factor Loadings } \\
\hline & & & & & F1 & F2 & F3 & F4 \\
\hline \multirow[t]{5}{*}{ Positive Feelings } & 17.91 & 3.70 & 13.66 & P_Feel1 & & & 0.80 & \\
\hline & & & & P_Feel2 & & & 0.78 & \\
\hline & & & & P_Feel4 & & & 0.83 & \\
\hline & & & & P_Feel5 & & & 0.60 & \\
\hline & & & & P_Feel6 & & & & \\
\hline \multirow{4}{*}{ Task Performance } & 14.73 & 2.85 & 8.10 & TSK_PER1 & & & & 0.87 \\
\hline & & & & TSK_PER2 & & & & 0.81 \\
\hline & & & & TSK_PER3 & & & & 0.79 \\
\hline & & & & TSK_PER4 & & & & 0.90 \\
\hline Cronbach's Alpha & & & & & 0.91 & 0.91 & 0.81 & 0.86 \\
\hline No. of Items remained & & & & & 6 & 9 & 5 & 4 \\
\hline $\begin{array}{l}\text { KMO measurement of } \\
\text { sampling adequacy }\end{array}$ & & & & & 0.82 & 0.85 & 0.77 & 0.76 \\
\hline $\begin{array}{l}\text { Approximate } \\
\text { Chi square }\end{array}$ & & & & & 361.74 & 370.51 & 137.38 & 156.76 \\
\hline Eigenvalues & & & & & 4.23 & 5.09 & 2.89 & 2.84 \\
\hline $\begin{array}{c}\text { Percent of } \\
\text { Variance explained \% }\end{array}$ & & & & & $70.46 \%$ & $56.51 \%$ & $57.81 \%$ & $70.87 \%$ \\
\hline
\end{tabular}

Note: F1: Self-efficacy, F2: Negative Feelings, F3: Positive Feelings, F4: Task Performance.

Additionally, Kaiser-Meyer-Olkin (KMO) and Bartlett's sphericity tests were evaluated in the EFA and the KMO achieved values greater than 0.6; the recommended values should be $\geq 0.5$ [89], with significant Chi square $(p=0.00)$ values. After conducting the EFA, the four factors were as follows: SEF (6 items), N_Feel (reduced to 9 items), P_Feel (reduced to 5 items), TSK_PER (4 items) with total 24 items.

A reliability test was then employed, Cronbach's alpha checking all variables against related items, with the cut-off recommended at 0.7 . All the results successfully exceeding this; refer to Table 2. Hence, it is evident that after this initial phase of evaluating the instrument, it was acceptable to move to the next phase of analysis, evaluating PLS-SEM's measurement and structural models. ANN was then applied to augment these results.

\subsection{Multivariate Assumptions}

PLS-SEM is a widely used robust analytical tool characterized by the following: (a) it does not require normal distribution of the dataset; (b) it is suitable for theory building or exploratory studies; (c) it is robust with a small sample size, in this case 83; and (d) it has the capability to maximize variance explained $[87,90,91]$. Although requires no prior assumption of normality, the results would be much improved if normally distributed; data far away from normality may inflate standard errors and reduce the probability of some relationships that can be considered significant [91].

In the following, multivariate analysis was performed to support the earlier results: normality, linearity and multicollinearity evaluation. In order to meet the assumption of normality, the graphical representation and evaluation of the normal Q-Q plot, detrended normal Q-Q plot, the normality histogram, in addition to analysis of skewness and kurtosis, were employed.

Checking the normal Q-Q plot and detrended normal Q-Q plot, the results emerged seem to have a satisfactory level of normality as points aligned with the line and are distributed normally in the normal Q-Q plot-refer to Figure 5. In addition, points are in the range of $[-3,+3]$ in detrended normal Q-Q plot (see Figure 6). Furthermore, in Figure 7, the histogram confirms the normality distribution. 


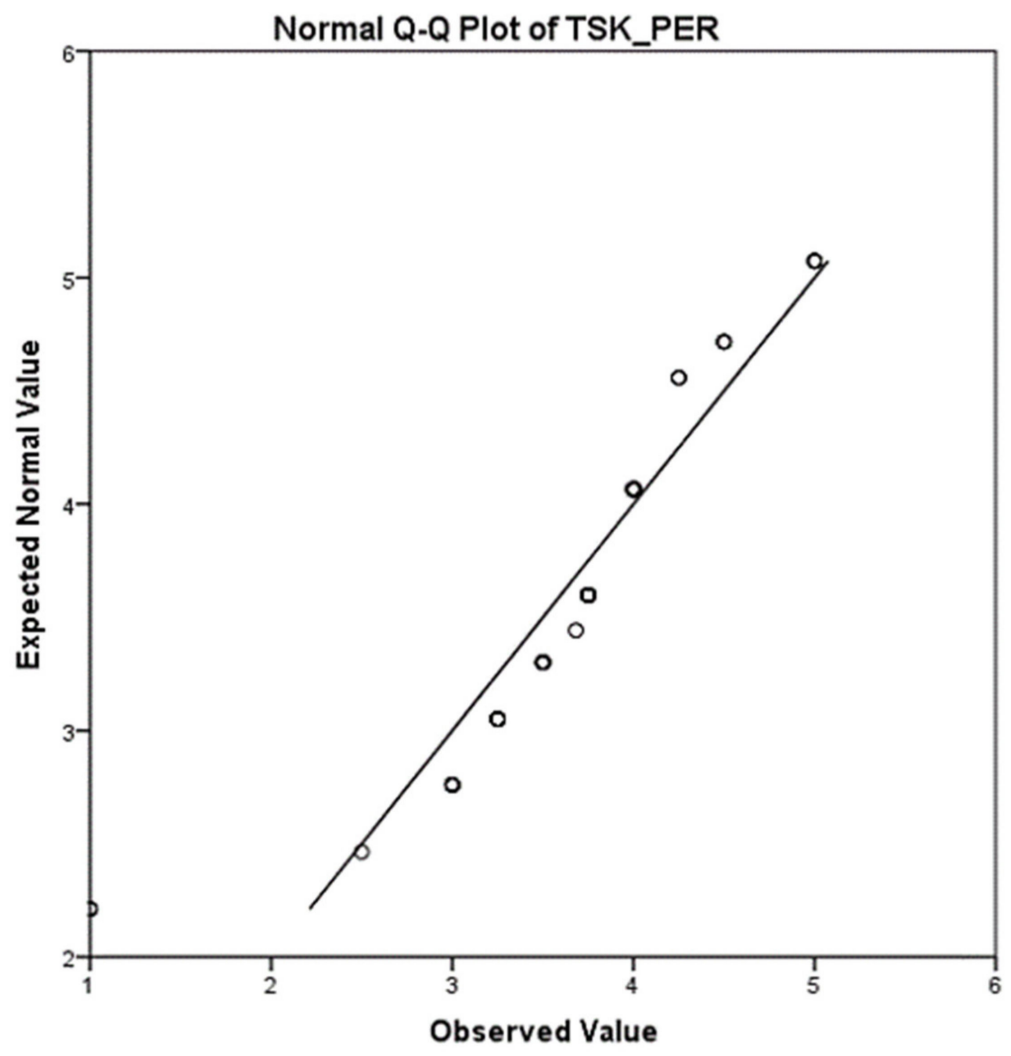

Figure 5. Normal Q-Q plot.

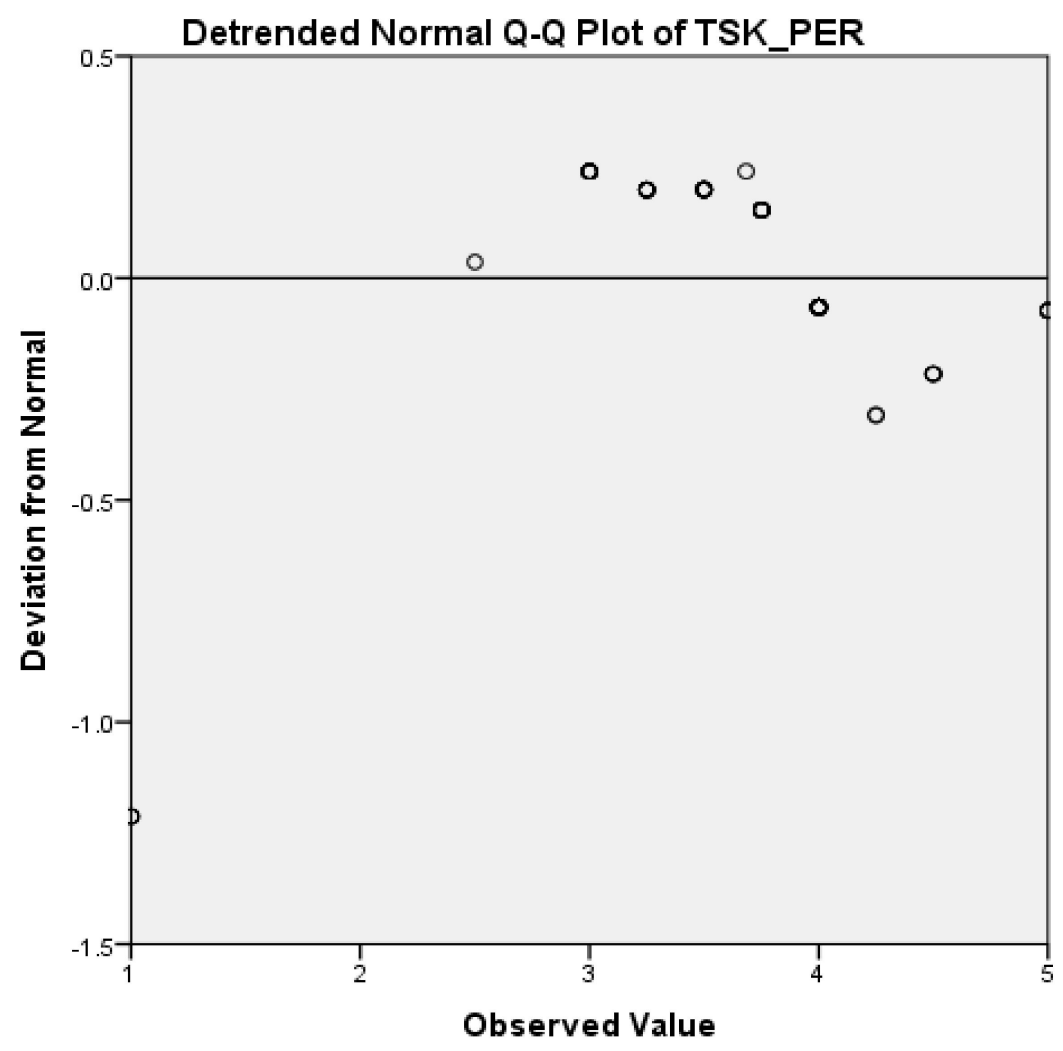

Figure 6. The Detrended Normal Q-Q Plot. 


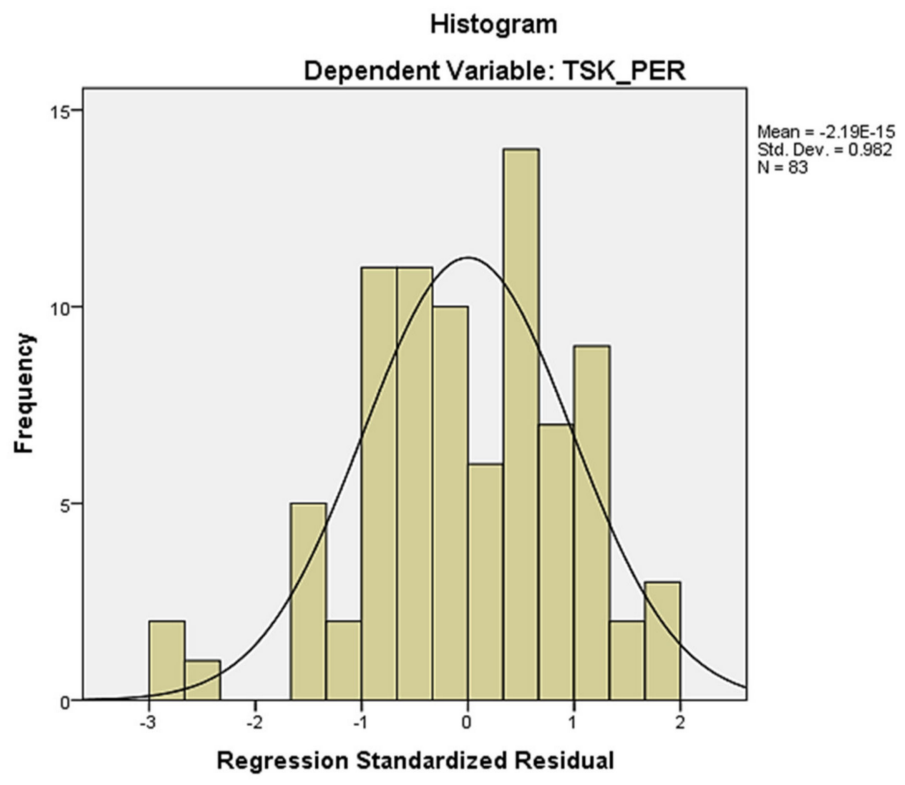

Figure 7. Normality distribution curve.

The rule of thumb for the skewness range with an acceptable index is to be less than the absolute value of 3 and the kurtosis to be less than 10 [92]. The obtained results ranges are as follows: $-1.42,0.71,-1.22,-1.173$ for SEF, N_Feel, P_Feel and TSK_PER, respectively. This is another indication of the normal distribution of the dataset.

The scatter plot in Figure 8 shows the linear relationship between the dependent variable (TSK_PER) and the standardized residuals. Figure 9 presents the standardized predicted values and the standardized residual in the relationship between the dependent (endogenous) and the independent (exogenous) variables, confirming the linearity. As no sign of cone or diamond appeared, equal variance dispersion or homoscedasticity was confirmed.

Scatterplot

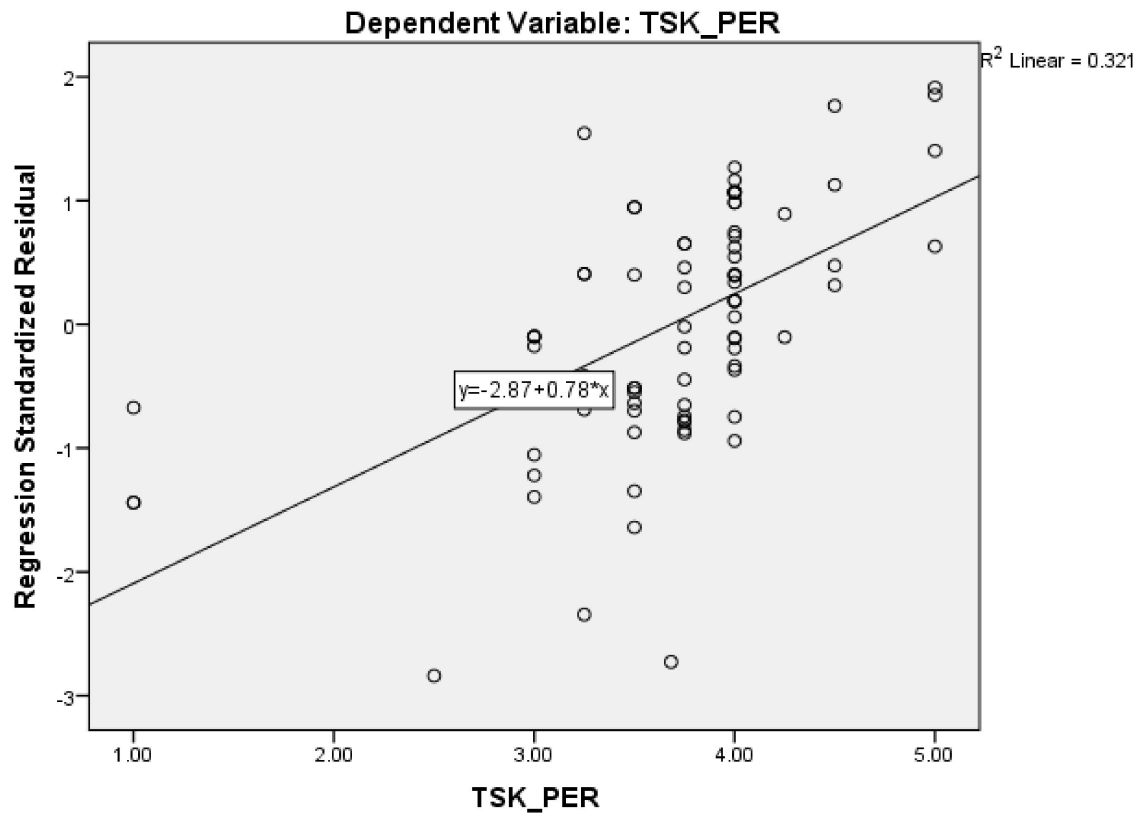

Figure 8. Regression standardized predicted values versus regression standardized residual. 


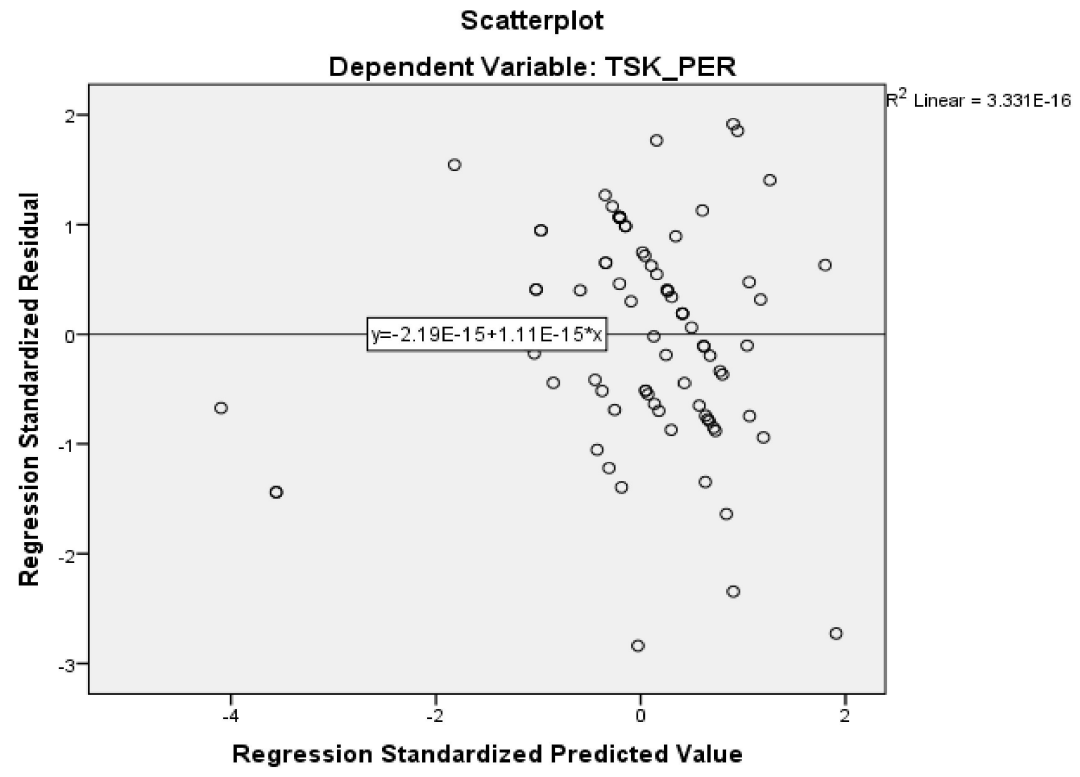

Figure 9. Dependent variable versus Regression standardized residual.

With regard to the investigation of multicollinearity issues, the Variance Inflation Factor (VIF) and the reciprocal tolerance value were checked. The rule of thumb indicates that if the value of VIF $>10$, the issue of multicollinearity holds. Tolerance, which corresponds to VIF, is another way to check for multicollinearity. A figure as low as 0.10 indicates multicollinearity in the dataset, otherwise values higher than 0.10 gives an indication of no issues of multicollinearity in the dataset [93]. Table 3 shows that no multicollinearity violations were found.

Table 3. Initial multicollinearity statistics.

\begin{tabular}{cccccccc}
\hline Model & Unstandardized Coefficients & $\begin{array}{c}\text { Standardized } \\
\text { Coefficients }\end{array}$ & $\boldsymbol{t}$ & Sig. & \multicolumn{2}{c}{ Collinearity Statistics } \\
\hline & B & Std. Error & Beta & & & Tolerance & VIF \\
\hline (Constant) & 1.534 & 0.373 & & 4.107 & 0.000 & & \\
SEF & 0.532 & 0.082 & 0.588 & 6.515 & 0.000 & 0.498 & 2.007 \\
N_Feel & -0.190 & 0.063 & -0.213 & -3.012 & 0.003 & 0.814 & 1.229 \\
P_Feel & 0.160 & 0.088 & 0.165 & 1.810 & 0.074 & 0.488 & 2.051 \\
\hline
\end{tabular}

Note: SEF: Self-efficacy, N_Feel: Negative Feelings, P_Feel: Positive Feelings.

\subsection{PLS-SEM Measurement Model Evaluation}

Before embarking on testing the hypotheses in PLS-SEM, the measurement model is evaluated by checking the following: (a) convergent validity, (b) outer loadings of items, (c) internal consistency and reliability and (d) discriminant validity. To test for convergent validity, the average variance extracted (AVE) and items' outer loadings were evaluated. The recommended value for AVE is equal to or higher than 0.5; our results show compliance with this criterion, with values ranging from 0.56 to 0.71 : see Table 4 .

The items' outer loadings are recommended to cross the cut-off values of 0.6 [94], although values of $0.5-0.6$ are acceptable for items in the development stage of a scale-as is the case of the current research-if there are no other indicators available for that construct [94]. The results confirmed compliance with the cut-off values: N_Feel (0.66-0.83), P_Feel (0.62-0.82), SEF (0.81-0.86), TSK_PER (0.79-0.89). Hence, the construct convergent validity was established. 
Table 4. Internal consistency and reliability and convergent validity.

\begin{tabular}{|c|c|c|c|c|c|c|}
\hline $\begin{array}{c}\text { Latent } \\
\text { Construct }\end{array}$ & Items & Loadings & AVE & CR & $\begin{array}{c}\text { Cronbach's } \\
\text { Alpha }\end{array}$ & roh_A \\
\hline \multirow[t]{9}{*}{ N_Feel } & N_Feel2 & 0.66 & 0.56 & 0.92 & 0.90 & 0.91 \\
\hline & N_Feel3 & 0.79 & & & & \\
\hline & N_Feel4 & 0.83 & & & & \\
\hline & N_Feel5 & 0.76 & & & & \\
\hline & N_Feel6 & 0.74 & & & & \\
\hline & N_Feel7 & 0.71 & & & & \\
\hline & N_Feel8 & 0.78 & & & & \\
\hline & N_Feel9 & 0.74 & & & & \\
\hline & N_Feel10 & 0.73 & & & & \\
\hline \multirow[t]{5}{*}{ P_Feel } & P_Feel1 & 0.79 & 0.58 & 0.87 & 0.81 & 0.82 \\
\hline & P_Feel2 & 0.75 & & & & \\
\hline & P_Feel4 & 0.82 & & & & \\
\hline & P_Feel5 & 0.62 & & & & \\
\hline & P_Feel6 & 0.80 & & & & \\
\hline \multirow[t]{4}{*}{ TSK_PER } & TSK_PER 1 & 0.87 & 0.71 & 0.91 & 0.86 & 0.86 \\
\hline & TSK_PER 2 & 0.81 & & & & \\
\hline & TSK_PER 3 & 0.79 & & & & \\
\hline & TSK_PER 4 & 0.89 & & & & \\
\hline \multirow[t]{6}{*}{ SEF } & SEF1 & 0.86 & 0.70 & 0.93 & 0.92 & 0.92 \\
\hline & SEF2 & 0.81 & & & & \\
\hline & SEF3 & 0.86 & & & & \\
\hline & SEF4 & 0.85 & & & & \\
\hline & SEF5 & 0.81 & & & & \\
\hline & SEF6 & 0.84 & & & & \\
\hline
\end{tabular}

Note: AVE: Average Values Extracted; CR: Composite Reliability.

The next step was to evaluate internal consistency and reliability by investigating composite reliability (CR) and Cronbach's alpha. The latter is a conservative measure and represents the lower bound of reliability, whereas $\mathrm{CR}$ represents the upper bound of reliability. Reporting both measures is recommended [91]. The CR cut-off values should be equal to or greater than 0.7 and Cronbach's alpha $(\alpha)$ not less than $0.60-0.70$ for all constructs in the model [91,95]. Table 4 shows that CR has values of $0.87-0.93$ and Cronbach's alpha $0.81-0.92$, confirming internal consistency and reliability. To sum up the findings from the two former steps, the constructs' convergent validity and internal consistency and reliability were confirmed.

As a final step in evaluation of the measurement model, the discriminant validity criterion is analyzed, in three main steps. First, Fornell and Larker's criterion [96] is checked; the square root of AVE in the diagonal should be greater than all off-diagonal values and Table 5 shows that this measure was fulfilled.

Table 5. Discriminant validity with Fornell-Larker criterion analysis.

\begin{tabular}{lllll}
\hline Latent Construct & $\mathbf{1}$ & $\mathbf{2}$ & $\mathbf{3}$ & $\mathbf{4}$ \\
\hline 1. N_Feel & $\mathbf{0 . 7 5}$ & & & \\
2. TSK_PER & -0.42 & $\mathbf{0 . 7 6}$ & & \\
3. P_Feel & -0.43 & 0.71 & $\mathbf{0 . 8 4}$ & $\mathbf{0 . 8 4}$ \\
4. SEF & -0.55 & 0.68 & 0.81 & \\
\hline
\end{tabular}

Note: Square root values (in bold) of AVE in the diagonal demonstrates values higher than off-diagonal.

Secondly, the cross-loading values of each item with its respective construct must correlate higher than with other constructs. Table 6 indicates that the results are congruent with this criterion. 
Table 6. Discriminant validity with cross-loading analysis.

\begin{tabular}{lcccc}
\hline & N_Feel & P_Feel & SEF & TSK_PER \\
\hline N_Feel2 & $\mathbf{0 . 6 6}$ & -0.21 & -0.32 & -0.39 \\
N_Feel3 & $\mathbf{0 . 7 9}$ & -0.38 & -0.26 & -0.36 \\
N_Feel4 & $\mathbf{0 . 8 3}$ & -0.34 & -0.33 & -0.46 \\
N_Feel5 & $\mathbf{0 . 7 6}$ & -0.34 & -0.44 & -0.49 \\
N_Feel6 & $\mathbf{0 . 7 4}$ & -0.15 & -0.12 & -0.31 \\
N_Feel7 & $\mathbf{0 . 7 1}$ & -0.38 & -0.23 & -0.41 \\
N_Feel8 & $\mathbf{0 . 7 8}$ & -0.26 & -0.22 & -0.29 \\
N_Feel9 & $\mathbf{0 . 7 4}$ & -0.42 & -0.37 & -0.41 \\
N_Feel10 & $\mathbf{0 . 7 3}$ & -0.29 & -0.40 & -0.47 \\
P_Feel1 & -0.34 & $\mathbf{0 . 7 9}$ & 0.50 & 0.57 \\
P_Feel2 & -0.40 & $\mathbf{0 . 7 5}$ & 0.48 & 0.48 \\
P_Feel4 & -0.19 & $\mathbf{0 . 8 2}$ & 0.60 & 0.47 \\
P_Feel5 & -0.29 & $\mathbf{0 . 6 2}$ & 0.47 & 0.48 \\
P_Feel6 & -0.38 & $\mathbf{0 . 8 0}$ & 0.63 & 0.59 \\
SEF1 & -0.36 & 0.67 & $\mathbf{0 . 8 6}$ & 0.63 \\
SEF2 & -0.26 & 0.51 & $\mathbf{0 . 8 1}$ & 0.60 \\
SEF3 & -0.26 & 0.63 & $\mathbf{0 . 8 6}$ & 0.63 \\
SEF4 & -0.41 & 0.60 & $\mathbf{0 . 8 5}$ & 0.80 \\
SEF5 & -0.39 & 0.62 & $\mathbf{0 . 8 1}$ & 0.66 \\
SEF6 & -0.43 & 0.54 & $\mathbf{0 . 8 4}$ & 0.73 \\
TSK_PER1 & -0.48 & 0.64 & 0.73 & $\mathbf{0 . 8 7}$ \\
TSK_PER 2 & -0.35 & 0.57 & 0.69 & $\mathbf{0 . 8 1}$ \\
TSK_PER 3 & -0.51 & 0.60 & 0.60 & $\mathbf{0 . 7 9}$ \\
TSK_PER 4 & -0.51 & 0.49 & 0.70 & $\mathbf{0 . 8 9}$
\end{tabular}

Note: The cross-loading values of each item with its respective construct (in bold) correlate higher than with other constructs.

As the final stage in this measurement evaluation process, the Heterotrait-Monotrait $\left(\mathrm{HTMT}_{\text {inference }}\right)$ is estimated for all constructs in the model. The rule of thumb is that no value of 1 should appears in the upper or lower confidence interval (CI) levels (i.e., LL $5 \%$ and UL 95\%) after running the bootstrapping routine [91]. The results confirm the requirements and give additional support for discriminant validity (see Table 7). Thus, proceeding to the structural model evaluation is warranted after the final measurement model is confirmed-refer to Figure 10.

Table 7. Discriminant validity with Heterotrait-Monotrait Ratio analysis.

\begin{tabular}{ccccc}
\hline Latent Construct & $\begin{array}{c}\text { Original } \\
\text { Sample }\end{array}$ & Mean & CI LL 5\% & UL 95\% \\
\hline P_Feel $\rightarrow$ N_Feel & 0.48 & 0.50 & 0.28 & 0.66 \\
SEF $\rightarrow$ N_Feel & 0.44 & 0.45 & 0.26 & 0.62 \\
SEF $\rightarrow$ P_Feel & 0.82 & 0.81 & 0.65 & 0.93 \\
TSK_PER $\rightarrow$ N_Feel & 0.60 & 0.60 & 0.39 & 0.77 \\
TSK_PER $\rightarrow$ P_Feel & 0.82 & 0.81 & 0.63 & 0.94 \\
TSK_PER $\rightarrow$ SEF & 0.91 & 0.90 & 0.81 & 0.96 \\
\hline
\end{tabular}

Note: LL: lower limit; UL: upper limit; CI: confidence interval.

\subsection{Hypothesis Testing with Structural Model Evaluation}

Before proceeding with evaluation of the structural model, collinearity is analyzed to ensure that they are not violating the issues of collinearity for the exogenous constructs on the endogenous constructs [91]. The results confirmed no violations of this measure as there were no VIF values above 5 , so collinearity was not an issue; see Table 8. 


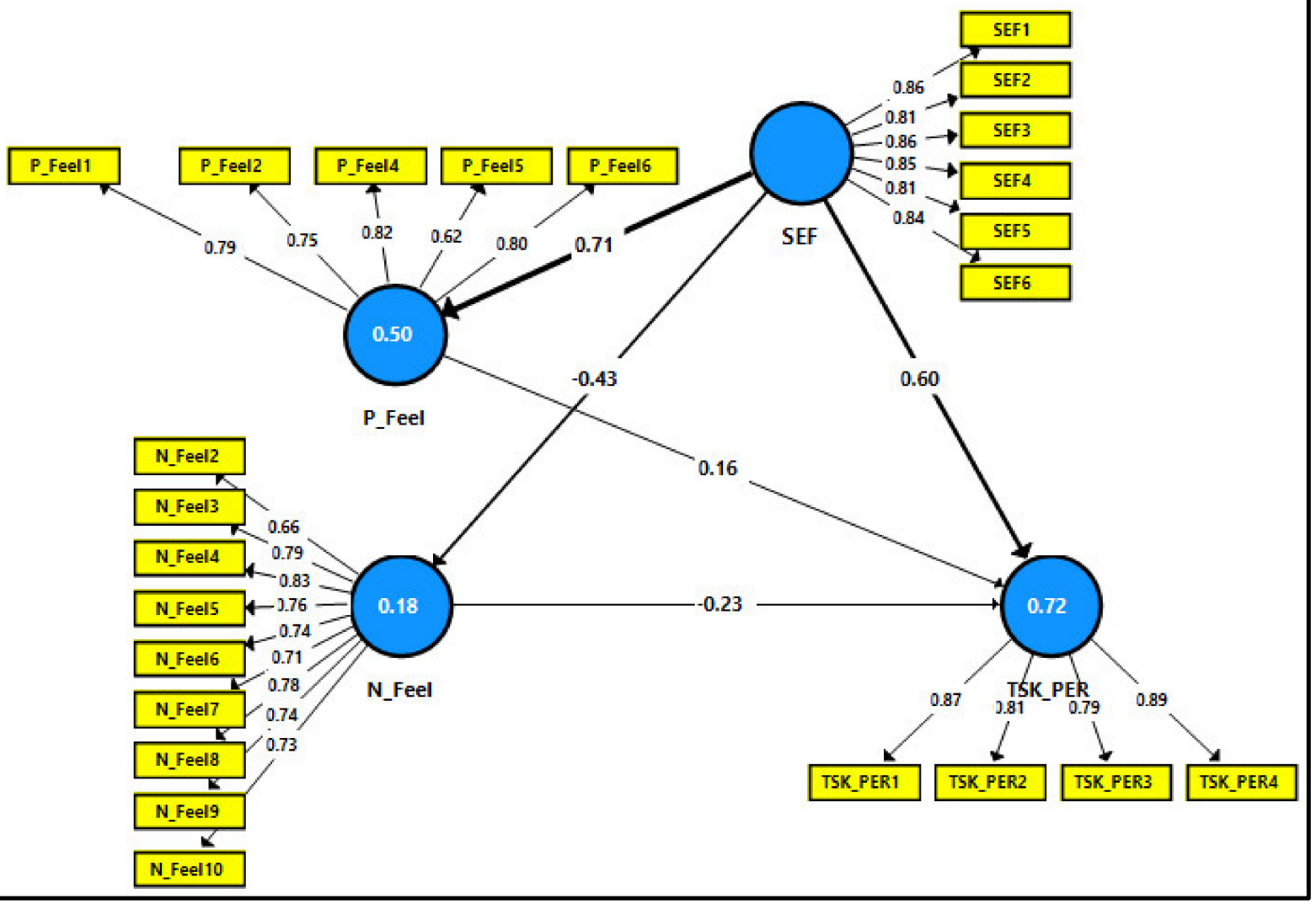

Figure 10. Measurement model results and the conceptual model of the research.

Table 8. Collinearity issues evaluation with VIF analysis.

\begin{tabular}{cccc}
\hline Latent Variable & N_Feel & P_Feel & TSK_PER \\
\hline N_Feel & & & 1.27 \\
P_Feel & & & 2.09 \\
SEF & 1.0 & 1.0 & 2.10 \\
\hline
\end{tabular}

Note: The recommended threshold of Variance Inflation Factor (VIF) is not to exceed 5.

Each predictor (i.e., exogenous or independent variable) construct was then checked against its endogenous (dependent variable) construct in order to identify the in-sample predictive power $\mathrm{R}^{2}$ (i.e., the coefficient of determination). The recommended $\mathrm{R}^{2}$ values $0.19,0.33,0.67$ are interpreted as weak, moderate and substantial, respectively [94]. In principle, $R^{2}$ is the variance explained by the predictor constructs and is considered a measure of the model's predictive accuracy [97]. The next step is to check the effect size $f^{2}$ for $\mathrm{R}^{2}$; the recommended values for effect sizes are described as small (0.02), medium (0.15) or large (0.35) [91].

As can be seen in Table 9, the explained variance of the dependent construct TSK-PER $\left(R^{2}=72 \%\right.$, substantial) is influenced by the three predictors SEF, N_Feel and P_Feel. The value of $R^{2}$ is considered especially promising in this exploratory model, showing the strength and the role of the three predictors in explaining the task performance of the academic and teaching staff during the pandemic. In addition, the effect sizes on task performance are as follows: for SEF it is large $\left(f^{2}=0.61\right)$, N_Feel medium $\left(f^{2}=0.15\right)$ and P_Feel weak $\left(f^{2}=0.05\right)$. These results explain the dominant role of SEF on performance, followed by negative feelings and, finally, positive feelings. An interesting point is that N-Feel clearly has a more influential role (i.e., negative) on TSK_PER than P_Feel during the coronavirus outbreak. This gives an indication of the dominant role of negative feelings on degrading one's performance to accomplish a certain task or attain a specific achievement 
during adversity and infection periods. Moreover, SEF explains $18 \%$ (i.e., weak) of the variance of N_Feel with a medium effect size $\left(f^{2}=0.22\right)$ and $50 \%$ (i.e., highly moderate) of the variance of P_Feel with a very large effect $\left(f^{2}=1.02\right)$. This can be interpreted as the strong role played by self-efficacy in reducing the effect of the negative feelings and increasing the positive feelings. These findings also underscore the vital role of SEF on both negative and positive feelings, reflecting its role on the emotions during the lockdown. Interestingly, SEF has more impact on P_Feel than on N_Feel.

Table 9. Coefficients of determination $\mathrm{R}^{2}$ and effect size $f^{2}$.

\begin{tabular}{|c|c|c|c|}
\hline Latent Constructs & N_Feel & P_Feel & TSK_PER \\
\hline $\begin{array}{l}\text { Coefficient of Determination } \mathrm{R}^{2} \\
\text { Effect size } f^{2}\end{array}$ & 0.18 & 0.50 & 0.72 \\
\hline N_Feel & & & 0.15 \\
\hline P_Feel & & & 0.05 \\
\hline SEF & 0.22 & 1.02 & 0.61 \\
\hline
\end{tabular}

In evaluating the hypotheses, of the current research, it should be remembered that this is an early-stage exploratory study measuring the variables during the COVID-19 outbreak. Therefore, the probability level assumes a $p$ value equal to or less than (0.10), corresponding to a two-tailed $t$ value of 1.65 [91]. Table 10 shows that the path coefficients of all the constructs have statistically significant relationships, supported by the $t$ values and the confidence intervals. Figure 11 illustrates the final structural model results.

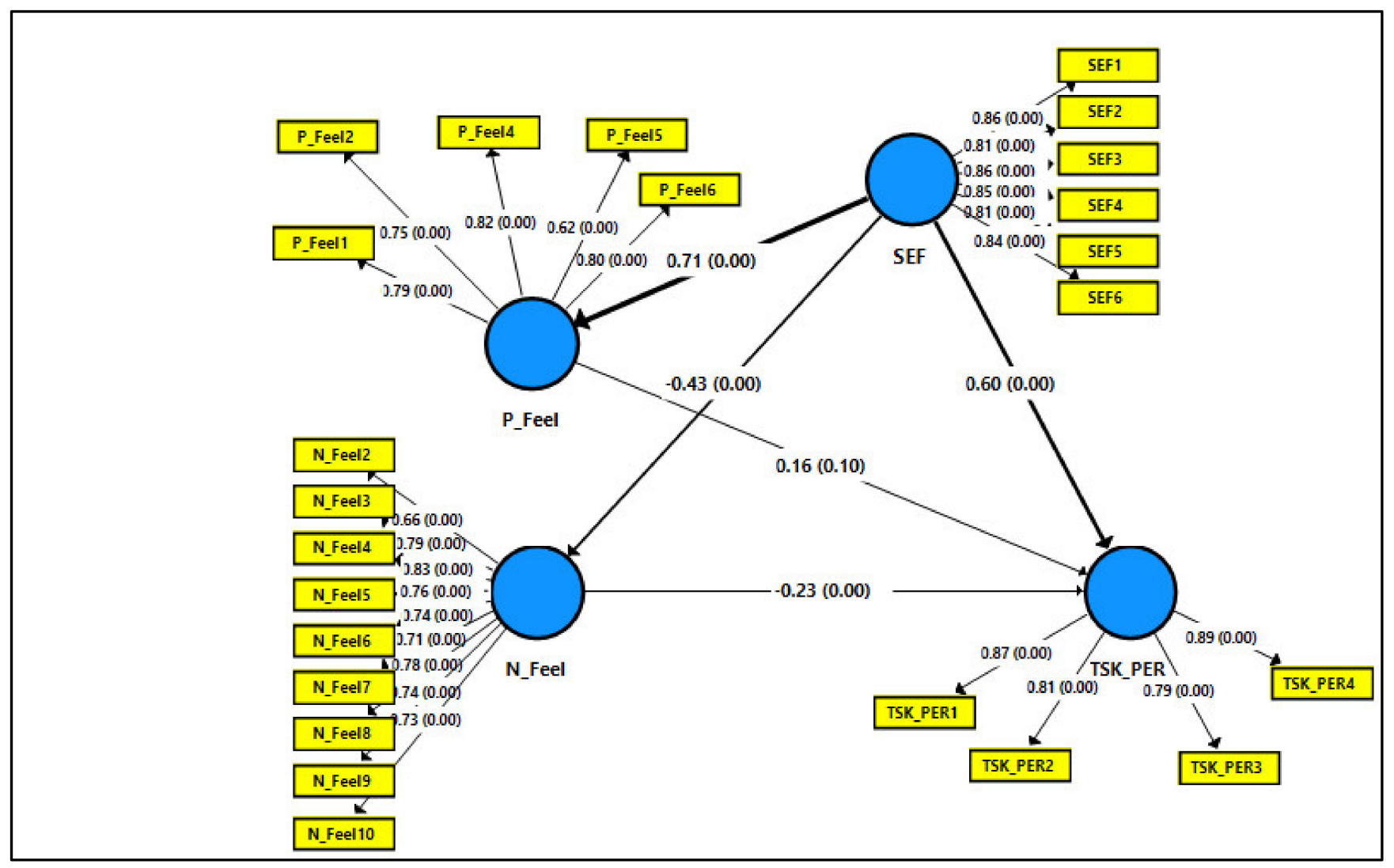

Figure 11. Structural model results. 
Table 10. Path coefficient and hypothesis testing.

\begin{tabular}{|c|c|c|c|c|c|c|c|c|}
\hline Path & Path Coefficients & Sample Mean & STDEV & $t$ Values & $p$ Values & $\begin{array}{c}\text { LL CI } \\
5 \%\end{array}$ & $\begin{array}{c}\text { UL CI } \\
95 \%\end{array}$ & $\begin{array}{c}\text { Hypotheses } \\
\text { Remarks }\end{array}$ \\
\hline N_Feel $\rightarrow$ TSK_PER & -0.23 & -0.23 & 0.07 & 3.07 & $0.00 * *$ & -0.35 & -0.11 & Supported \\
\hline P_Feel $\rightarrow$ TSK_PER & 0.16 & 0.16 & 0.10 & 1.66 & $0.10 *$ & 0.01 & 0.33 & Supported \\
\hline SEF $\rightarrow$ N_Feel & -0.43 & -0.44 & 0.13 & 3.33 & $0.00 * *$ & -0.59 & -0.20 & Supported \\
\hline SEF $\rightarrow$ P_Feel & 0.71 & 0.71 & 0.08 & 9.01 & $0.00 * *$ & 0.55 & 0.82 & Supported \\
\hline SEF $\rightarrow$ TSK__PER & 0.60 & 0.59 & 0.09 & 6.73 & $0.00 * *$ & 0.46 & 0.75 & Supported \\
\hline
\end{tabular}

Note: CI: confidence interval; LL: lower limit; UL: upper limit. ${ }^{*} p<0.10 ;{ }^{* *} p<0.01$.

\subsubsection{The Relationship N_Feel $\rightarrow$ TSK_PER}

In more detail, Table 10 indicates that the path N_Feel $\rightarrow$ TSK_PER is statistically significant $(\beta=-0.23, p<0.10, t=3.07)$ with a supporting confidence interval with bias corrected [-0.35--0.11]; hence, $\mathrm{H} 1$ is supported. The findings show that the impact of negative feelings on the tasks performed by the academic and teaching staff should not be neglected as a consequence of the pandemic and lockdown. Previous studies have indicated that COVID-19 affects the mental wellbeing of individuals [45-48]. Therefore, a sense of fear, anxiety, boredom, frustration, disappointment, exhaustion and uncertainty can severely impact performance and should not be ignored. Negative feelings can damage judgment and problem-solving strategies in the event of hardship and adversity $[54,55]$. Additionally, adjusting to online teaching is coupled with stress, challenges and negative feelings, with the burden of more hours and more effort in order to meet the institution's task goals or face dismissal. That is, these results support hypothesis H1.

\subsubsection{The Relationship P_Feel $\rightarrow$ TSK-PER}

Similarly, Table 10 shows that the path P_Feel $\rightarrow$ TSK-PER is statistically significant ( $\beta=0.16, p \leq 0.10, t=1.66$ ) with supporting confidence interval with bias corrected and accelerated [0.01-0.33]; hence, $\mathrm{H} 2$ is supported. This is confirmed by the empirical evidence, that positive feelings emerged as an influencer on the performance of the academic and teaching staff. The more positive the emotions, the better performance is achieved. The positivity felt is perceived to help in adjusting their strategies to meet the institution 's goals and to overcome the difficult situation suddenly encountered and improving their performance. In addition, the positive feelings create a sense of optimism, which influences psychological and physiological wellbeing [55] and is a key factor in sustaining and improving productivity and performance. Support from the institution, the family and colleagues are other elements which boost morale and increase the commitment. This support can take different forms such as chatting with colleagues, friends, or relatives and hearing good news of the recovery. Sport is another important factor for the mental well-being and the positivity of oneself. Therefore, practicing sport in-house can raise the positive feelings and hence, sustaining the performance that is accompanied by optimism and motivation. Based on the perceptions received from the respondents, the empirical evidence supports hypothesis $\mathrm{H} 2$.

\subsubsection{The Relationship SEF $\rightarrow$ TSK-PER}

Thirdly, Table 10 shows that self-efficacy has a statistically significant $(\beta=0.60, p \leq 0.10$, $t=6.73$ ) relationship with TSK-PER, supported by a confidence interval with bias corrected and accelerated [0.46-0.75]; therefore, $\mathrm{H} 3$ is supported. SEF also emerged as having the most significant effect on TSK_PER and playing a crucial role in critical situations such as COVID-19. This result is not surprising in the light of previous works [59,63]. Self-efficacy reflects the inner belief in one's capabilities, competency, skills, patience, indomitable will and intellect to achieve assigned tasks and face difficult situations. Therefore, possessing high self-efficacy is expected to set challenging goals, preserve commitment and can overcome the hardships and adversity that may be encountered in life and workplace. Through their skill, motivation and eagerness to discover the unknown, the academic/teaching staff can devote themselves to learning new skills, adapting to the advent of the coron- 
avirus and coping with the challenges to better achieve the academic tasks professionally, effectively, efficiently and on-time. SEF emerged as the strongest motivator toward the execution of duties to deliver course content digitally to students, achieve academic goals and perform well during COVID-19. The result agrees with the findings of $[57,98]$ in that self-efficacy is a driver of performance [64]. Hence, possessing a high level of self-efficacy is imperative during the era of COVID-19, especially with the transition from traditional education to online.

\subsubsection{The Relationships SEF $\rightarrow$ N_Feel and SEF $\rightarrow$ P_Feel}

Finally, Table 10 indicates that self-efficacy has a statistically significant $(\beta=-0.43$, $p \leq 0.10, t=3.3$ ) relationship with $N_{-}$Feel, with a supporting confidence interval with bias corrected and accelerated [ $-0.59-0.20]$; therefore, H4 is supported. Similarly, self-efficacy has a statistically significant $(\beta=0.71, p \leq 0.10, t=9.01)$ correlation with $P_{-}$Feel, supported by the confidence interval with bias corrected and accelerated [ $-0.59--0.20]$; hence, H5 is supported. To explain, when the educator possesses a high self-efficacy, he/she gains confidence on him/herself and this, in turn, reduces fear, stress and anxiety felt, as well as mitigates disappointment of the situation or frustration of completing the educational tasks as imposed by the management of the institution. Another point worth mentioning is that the self-efficacy reinforces the trust that one has on his/her competencies and is likely to enhance the positive feelings that he/she possesses. In turn, this positivity would drive to better perform in the pedagogical process during the lockdown. In principle, it has been clearly expressed that the effect of self-efficacy on performance is evident and related to one's skills to fulfill a specific task in certain context while possessing the adaptation to changes of the environment [56]. In addition, those who have high self-efficacy are more likely to apt to choose challenging situations with extended motivations and efforts in order to succeed in achieving their objectives especially when obstacles or complex situations lay in their way [56,62].

On the other hand, those with negative feelings, self-efficacy can help in reducing their negativity, but the degree of effectiveness is lesser than the effect on those with positive feelings. This can be returned to the fact that those with negative feelings lacks the trust/confidence on themselves to a higher degree and self-efficacy could reduce it until they return to their mental balance and well-being. In addition, those with negative feelings have a more tendency to avoid things and to escape from unknow or difficult situations than those with positive feelings who have the courage, trust on their competencies and eagerness to encounter the unknow or uncertain.

Overall, the relationship SEF $\rightarrow$ P_Feel is much stronger than SEF $\rightarrow$ N_Feel. This underscores the importance of self-efficacy on positive feelings and can be said that the more trust and confidence on one's capabilities, skills, patience, intellectual, indomitable will and competences, the more likely this would drive one's attention to perform well in the tasks assigned to him/her. As indicated in literature the educator is required to have or develop more skills in using or applying different technological devices and applications, building social and creative teaching skills to deal with the new style of online teaching [61]. Hence, possessing self-efficacy is imperative during the ear of COVID-19 especially with the transition from traditional education to online. Figure 11 illustrates the structural and hypotheses results of the proposed model.

\subsection{Neural Network Analysis and Results}

\subsubsection{The Structure of the ANN Model}

The model of the neural network was developed here using SPSS 24. The first part of the analysis was to define the number of output layers, input layers and hidden layers. Other aspects included defining the number of neurons, the activations' function algorithms and the sample size of the training and test sets. The number of input layers depends on the number of attributes or predictors, in this case the three latent constructs in Model A (SEF, N_Feel and P_Feel) and one (SEF) in Models B and C. Another important consideration 
is that this phase of analysis depends only on selecting the significant relationships that emerged from the PLS-SEM analyses. In addition, the model is divided into three models, namely: Model A (i.e., the direct relationship between SEF, N_Feel and P_Feel and the dependent variable TSK_PER), Model B (i.e., the relationship between SEF and N_Feel) and Model C (i.e., the relationship between SEF and P_Feel). Pertaining to the number of output layers, there is only one neuron for each of the three models as there is only one dependent variable for the main model, i.e., Model A; one for Model B (i.e., N_Feel) and for Model C (dependent variable P_Feel).

Furthermore, the number of hidden layers is one as the model is not complex and the sample not large. With regard to the number of neurons in the hidden layers, the research followed previous works in starting the number of neurons at one and increasing by one in each run of the ANN analysis, up to ten. The results of each run were reported. To overcome overfitting, a ten-fold approach with 10\% sample size of the test set and $90 \%$ sample size of the training set was applied. The hyperbolic tangent activation function was selected in the hidden layer and the identity function in the output based on the continuous scaled nature of the output. In principle, the sigmoid activation function is used merely when the output layer has a binary or multicast categorical dependent function.

\subsubsection{The Model Performance and Independent Variable Importance Analysis}

The purpose of using ANN is to evaluate the model's performance accuracy $[69,70,76]$. For the main model, Model A, the root mean square error (RMSE) value was computed in order to achieve this objective and to define the relative importance of the predictor on TSK_PER. As can be seen from Table 11, the average RMSE mean values calculated for the training and testing sets are small, 0.079 and 0.056 with standard deviation of 0.02 and 0.09 , respectively. The RMSE values in the test set are less than the value in the training set. This clearly indicates improvement of the prediction process by utilizing the training dataset as a reference; refer to Figure 12. In addition, the small RMSE mean values indicates that the ANN model offers a high prediction accuracy with less error and fits the data very well [68,71,99-101].

For the sub-model results, Model B was $(\mathrm{RMSE}=0.136, \mathrm{STD}=0.010)$ for the training set and for the test set (RMSE $=0.109$, STD $=0.037$ ), whereas in Model $C$ the results for the training set were $(\mathrm{RMSE}=0.099, \mathrm{STD}=0.010)$ and for the test set $(\mathrm{RMSE}=0.112$, STD $=0.072)($ see Table 12).

To evaluate the contribution of every predictor variable on the dependent variable in the three models, the average of the relative importance and the normalized percentages was calculated, as presented in Table 13. For the normalized predictor's importance percentage-sometimes called the sensitivity analysis-the calculations are based on the ratio of the relative importance value of each predictor divided by the highest relative importance value obtained $[68,69,76,79,80]$. Furthermore, in Table 13 , the sample sizes of the testing and training sets are presented for each neural network. The sample sizes vary based on the division made by the SPSS; however, the total dataset was retained, i.e., 83 cases. The sum of squares errors (SSE), mean and standard deviations (STD) are also illustrated.

Before analyzing the relative independent variable importance, we specified the three models, A, B and C. Models B and C have only one predictor, so no comparison could be made. This is one of the weaknesses of ANN, in predicting the strength of complex and non-direct relationships. On the other hand, for Model A the results of the normalized values show that SEF was by far the most significant variable in the relationship with TSK_PER $(100 \%)$, agreeing with the results obtained from PLS-SEM. However, P_Feel $(52.68 \%)$ came next, followed by N_Feel (43.75\%). Interestingly, these results contradict those of PLS-SEM, where P-Feel was in the third position. These contradictions may be attributed to the ability of the ANN model to deal with non-linear and non-compensatory nature of the data, as well as its greater ability to learn and predict with accuracy [76]. 
Table 11. Model A Predictive accuracy.

\begin{tabular}{|c|c|c|c|c|c|c|}
\hline Neural Network No. & Training Sample Size & RMSE-Training & SSEs & Testing Sample Size & RMSE-Testing & SSEs \\
\hline ANN1 & 74 & 0.072 & 0.382 & 9 & 0.046 & 0.019 \\
\hline ANN2 & 75 & 0.073 & 0.395 & 8 & 0.060 & 0.029 \\
\hline ANN3 & 74 & 0.073 & 0.393 & 9 & 0.047 & 0.02 \\
\hline ANN4 & 75 & 0.073 & 0.398 & 8 & 0.056 & 0.025 \\
\hline ANN5 & 70 & 0.133 & 1.231 & 13 & 0.056 & 0.041 \\
\hline ANN6 & 72 & 0.066 & 0.309 & 11 & 0.073 & 0.059 \\
\hline ANN7 & 73 & 0.070 & 0.358 & 10 & 0.050 & 0.025 \\
\hline ANN8 & 76 & 0.074 & 0.421 & 7 & 0.043 & 0.013 \\
\hline ANN9 & 73 & 0.070 & 0.354 & 10 & 0.062 & 0.039 \\
\hline ANN10 & 77 & 0.085 & 0.559 & 6 & 0.065 & 0.025 \\
\hline Mean & & 0.079 & 0.480 & & 0.056 & 0.0295 \\
\hline Standard Deviation & & 0.020 & & & 0.090 & \\
\hline
\end{tabular}

Note: SSE: Sum of squares error, RMSE: root mean square error and ANN: artificial neural network neuron.

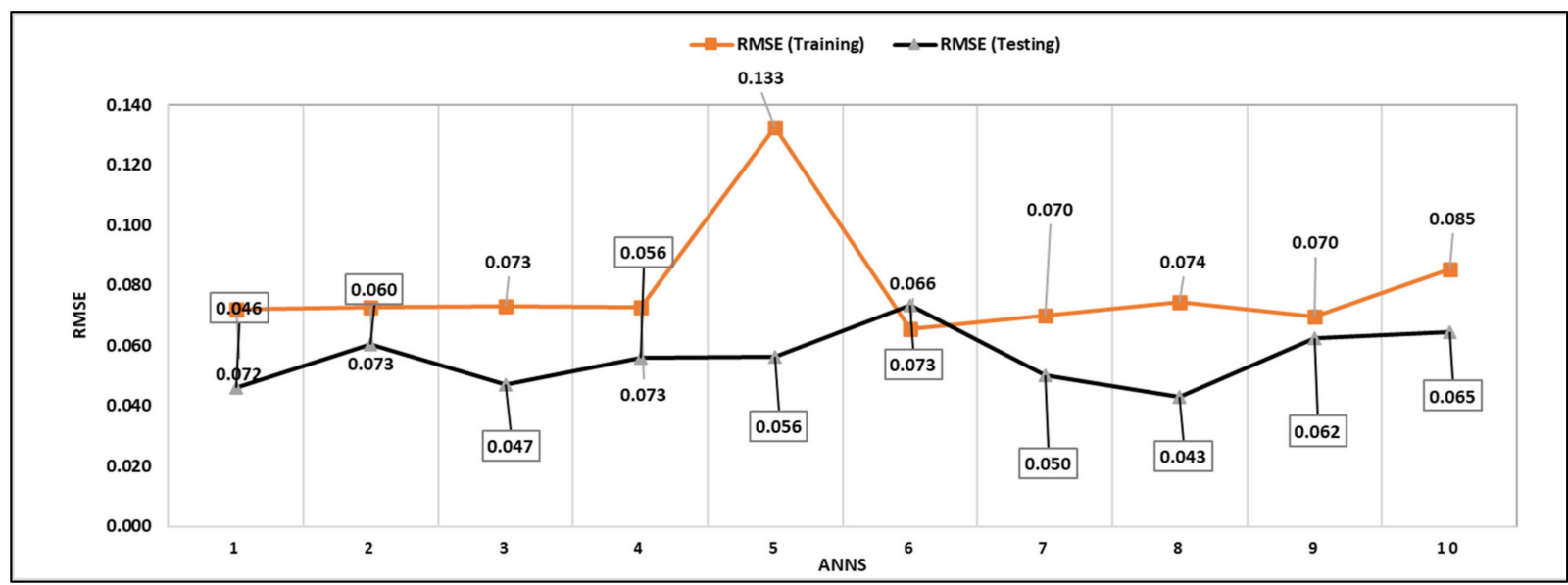

Figure 12. RMSE relationship between training and testing in Model A.

Table 12. Model B and Model C Predictive Accuracy.

\begin{tabular}{|c|c|c|c|c|c|c|}
\hline \multirow{2}{*}{ Neural Network No. } & \multicolumn{6}{|c|}{ Model B with an Input Neuron SEF and Output Neuron $P_{-}$Feel } \\
\hline & Training Sample Size & RMSE-Training & SSEs & Testing Sample Size & RMSE-Testing & SSEs \\
\hline ANN1 & 75 & 0.141 & 1.487 & 8 & 0.135 & 0.145 \\
\hline ANN2 & 72 & 0.127 & 1.153 & 11 & 0.131 & 0.188 \\
\hline ANN3 & 75 & 0.141 & 1.496 & 8 & 0.087 & 0.061 \\
\hline ANN4 & 71 & 0.127 & 1.141 & 12 & 0.146 & 0.257 \\
\hline ANN5 & 73 & 0.149 & 1.631 & 10 & 0.101 & 0.103 \\
\hline ANN6 & 73 & 0.126 & 1.157 & 10 & 0.133 & 0.176 \\
\hline ANN7 & 74 & 0.128 & 1.219 & 9 & 0.115 & 0.12 \\
\hline ANN8 & 80 & 0.130 & 1.347 & 3 & 0.018 & 0.001 \\
\hline ANN9 & 75 & 0.150 & 1.685 & 8 & 0.097 & 0.075 \\
\hline ANN10 & 74 & 0.144 & 1.526 & 9 & 0.122 & 0.133 \\
\hline Mean & & 0.136 & 1.384 & & 0.109 & 0.126 \\
\hline Standard Deviation & & 0.010 & & & 0.037 & \\
\hline \multirow{2}{*}{ Neural Network No. } & \multicolumn{6}{|c|}{ Model $C$ with an Input Neuron SEF and Output Neuron $P_{-}$Feel } \\
\hline & Training Sample size & RMSE-Training & SSEs & Testing Sample size & RMSE-Testing & SSES \\
\hline ANN1 & 77 & 0.098 & 0.741 & 6 & 0.061 & 0.022 \\
\hline ANN2 & 79 & 0.104 & 0.85 & 4 & 0.097 & 0.038 \\
\hline ANN3 & 77 & 0.096 & 0.705 & 6 & 0.055 & 0.018 \\
\hline ANN4 & 74 & 0.094 & 0.651 & 9 & 0.242 & 0.527 \\
\hline ANN5 & 75 & 0.092 & 0.629 & 8 & 0.085 & 0.058 \\
\hline ANN6 & 76 & 0.125 & 1.193 & 7 & 0.110 & 0.084 \\
\hline ANN7 & 77 & 0.089 & 0.61 & 6 & 0.112 & 0.075 \\
\hline ANN8 & 76 & 0.095 & 0.682 & 7 & 0.038 & 0.01 \\
\hline ANN9 & 74 & 0.094 & 0.655 & 9 & 0.240 & 0.517 \\
\hline ANN10 & 77 & 0.099 & 0.757 & 6 & 0.079 & 0.037 \\
\hline Mean & & 0.099 & 0.747 & & 0.112 & 0.1386 \\
\hline Standard Deviation & & 0.010 & & & 0.072 & \\
\hline
\end{tabular}

Note: Values in bold represent SSE: sum of squares error, RMSE: root mean square error and ANN: artificial neural network neuron. 
Table 13. Relative Independent Variable Importance.

\begin{tabular}{ccc}
\hline \multirow{2}{*}{ Latent Construct Input } & Model A with TSK_PER Output & Normalized Importance $\%$ \\
\cline { 2 - 3 } & Relative Importance & $100 \%$ \\
SEF & 0.560 & $43.75 \%$ \\
N_Feel & 0.245 & $52.68 \%$ \\
P_Feel & 0.295 & $100 \%$ \\
SEF & Model B with N_Feel output & 1 \\
SEF & Model C with N_Feel output & $100 \%$ \\
\hline
\end{tabular}

\section{Conclusions, Implications and Limitations}

The purpose of the current study is to explore the effects of N_Feel and P_Feel, as well as SEF, on TSK_PER in the academic and teaching staff in Bahrain during the COVID19 lockdown. In addition, the role of SEF on N_Feel and P_Feel was further explored. To achieve the goals of the research, a model was proposed and successfully evaluated; hence, one research question was answered. Further research questions were answered by testing the hypotheses, which were all supported. The dual analysis approach, i.e., using PLS-SEM and MLP-ANN, was used and probed in the literature in terms of the difference between them, the pros and cons and their complementary role in augmenting and bringing new insights to the findings. The linear (SEM) and non-linear (ANN) relationships were evaluated using the strength of both approaches. In addition, the causal relationships tested by SEM and the predictive power of ANN further augmented the revealed results and answering the remaining research questions.

This research is considered among the pioneers in its field in terms of the coherent and rigorous methodology employed in the instrument development and analyses conducted. In addition, the proposed model is considered unique in the relationships postulated and explored, with new dimensions of the effects of COVID-19 on the teaching and academic sector performance in continuing their work from home despite the obstacles and negative emotions that emerged.

The findings of this study contribute to the body of knowledge by offering insights into the significant and negative effect of N_Feel on the performance of academic/teaching staff. P_Feel also appeared to influence performance. Above all, that the respondents' selfefficacy, whether already possessed or learned, emerged as the most significant element influencing task performance during lockdown. The findings also indicate the crucial role of SEF on the positive and negative feelings towards achieving the tasks. SEF has a negative and statistically significant impact on reducing the negative feelings and a positive and significant effect on increasing the positive feelings. This means that each new skill learned or possessed can provide a scaffolding to enable the academic and teaching staff to cope with the emergent adversities and stressful times, as well as to help in achieving the assigned tasks.

Furthermore, by exploring these newly postulated relationships, new insights are gained into the effect of the three independent constructs on performance. Unlike prior research examining the predictors of task performance, this study took the initiative to explore the relationships of these new variables with TSK_PER, explaining its importance and contribution in the body of knowledge and filling the gap in the literature, by studying such effects on task performance during emergency situations, adversity, hardships, catastrophic events and lockdowns. The findings have also proven the crucial role of SEF in promoting positive feelings and reducing negative feelings, in turns increasing task performance. Consequently, the study underscores the importance of N_Feel, P_Feel and SEF being included in future research models during a pandemic or catastrophic event, especially with their proven measurements developed and examined. As a future direction, the model postulated in this research has proven its predictive power/accuracy and can 
be used and/or extended with other constructs with proven convergent validity, internal consistency, reliability and discriminant validity.

\subsection{Practical Implications}

Since this research validated the significant impact of self-efficacy and positive and negative feelings on the performance of the academic and teaching staff during the lockdown, the university management should stimulate the positive feelings and eliminate the negative ones by: (a) sending encouraging messages, (b) offering promotions and certificates of achievement, (c) showing positive communication, listening to suggestions and worries, (d) providing technical or resilience training, (e) brainstorming new ideas to improve the unprecedented situation and (f) raising morale from time to time in order to create a positive workplace environment. By following this powerful strategy, the staff will be positive and mentally stable and the work retain its stability, as it was in the pre-COVID19 era. In particular, self-efficacy has been shown in this study to be a very important factor and should be encouraged; raising positive feelings and reducing the negative ones, in turn, helping staff to trust their own capabilities and competencies in overcoming new problems and dealing with new polices, teaching styles, or software packages. Human resource management should therefore focus on training for psychological wellbeing and developing technical skills.

\subsection{Limitations and Future Directions}

This study, as in any scientific exploratory work, has limitations that could be eliminated by conducting further research and exploration on the topic. Limitations include the small sample size from Bahraini universities, due to the lockdown and the small response from already over-burdened individuals. Therefore, future research with more respondents would present a larger picture of the situation in Bahrain. Secondly, the study targeted the Arab context; it would be more insightful to conduct comparative studies in different cultures (e.g., Asian, eastern/western European, or African).

This research was a cross-sectional study. To achieve a greater impact, a longitudinal study that considers responses before, during and after COVID-19 with a larger audience is strongly recommended. The research used a limited number of constructs to test their effect on performance, as well as the role of self-efficacy. It would appropriate to add additional constructs such as ease of use of the tools/programs used in the teaching methods, the perceived usefulness, the trustworthiness of management and students, the perceived risks while facing the critical times of the pandemic and the socio-demographics (e.g., level of education, age, gender, income, marital status and being alone or with others at home).

Author Contributions: Conceptualization, G.A.-M.T.-H. and A.S.; software, G.A.-M.T.-H.; validation, G.A.-M.T.-H., I.T.H.; formal analysis, G.A.-M.T.-H., investigation, G.A.-M.T.-H. and A.S.; resources, G.A.-M.T.-H. and A.S.; data curation, A.S. and G.A.-M.T.-H.; writing-original draft preparation, G.A.-M.T.-H.; writing-review and editing, I.T.H.; visualization, I.T.H.; supervision, A.S.; funding acquisition, I.T.H. All authors have read and agreed to the published version of the manuscript.

Funding: This research received no external funding.

Institutional Review Board Statement: Not applicable.

Informed Consent Statement: Not applicable.

Data Availability Statement: Available upon request.

Conflicts of Interest: The authors declare no conflict of interest. 


\section{Appendix A}

Table A1. Survey Instrument.

\begin{tabular}{|c|c|c|c|}
\hline Latent Variable & Item/Indicator & Coding & Remarks \\
\hline \multirow[t]{4}{*}{ Task Performance (TSK_PER) } & $\begin{array}{l}\text { During the COVID-19 pandemic, I } \\
\text { managed to plan transformation of my } \\
\text { classes into digital media/live streaming } \\
\text { using remote tools so that it is done } \\
\text { on time. }\end{array}$ & TSK_PER1 & [43] \\
\hline & $\begin{array}{l}\text { During the COVID- } 19 \text { pandemic, my } \\
\text { planning on the transformation of my } \\
\text { classes into media/live streaming using } \\
\text { remote tools is optimal. }\end{array}$ & TSK_PER2 & [43] \\
\hline & $\begin{array}{l}\text { During the COVID-19 pandemic, I kept in } \\
\text { mind upskilling and the lessons that I } \\
\text { learned during the teaching sessions or } \\
\text { transformation of courses to save my time, } \\
\text { efforts and hard work in the future }\end{array}$ & TSK_PER3 & {$[43]$} \\
\hline & $\begin{array}{l}\text { During the COVID-19 pandemic, I was able } \\
\text { to separate main issues from side issues } \\
\text { encountered during the transformation of } \\
\text { classes into digital media or live streaming. }\end{array}$ & TSK_PER4 & [43] \\
\hline \multirow[t]{6}{*}{ Positive Feelings (P_Feel) } & $\begin{array}{l}\text { During the COVID-19 pandemic, I obtain } \\
\text { support to maintain morale from my } \\
\text { institution and/or colleagues. }\end{array}$ & P_Feel1 & Author-developed item \\
\hline & $\begin{array}{l}\text { 2. During the COVID-19 pandemic, I find } \\
\text { relief through exploring social media } \\
\text { websites (e.g., Facebook, Twitter, } \\
\text { Instagram, Telegram, etc.) }\end{array}$ & P_Feel2 & Author-developed item \\
\hline & $\begin{array}{l}\text { During the COVID-19 pandemic, I feel } \\
\text { positive through practicing sports in-house }\end{array}$ & P_Feel3 & $\begin{array}{l}\text { Author-developed item. Eliminated } \\
\text { because it is below the recommended } \\
\text { cut-off value of loadings }(0.55)\end{array}$ \\
\hline & $\begin{array}{l}\text { During the COVID-19 pandemic, I feel } \\
\text { positively joyful when chatting with my } \\
\text { colleagues in various social media apps }\end{array}$ & P_Feel4 & Author-developed item \\
\hline & $\begin{array}{l}\text { During the COVID- } 19 \text { pandemic, I get a } \\
\text { better mood when chatting with my } \\
\text { children and/or my wife. }\end{array}$ & P_Feel5 & Author-developed item \\
\hline & $\begin{array}{l}\text { During the COVID-19 pandemic, I feel } \\
\text { cheerful when hearing good news of } \\
\text { decreasing numbers of infected people. }\end{array}$ & P_Feel6 & Author-developed item \\
\hline \multirow[t]{10}{*}{ Negative Feelings (N_Feel) } & $\begin{array}{l}\text { COVID-19 put my future financial } \\
\text { arrangements and plans in doubt }\end{array}$ & N_Feel1 & $\begin{array}{l}\text { Author-developed item. Eliminated } \\
\text { because it is below the recommended } \\
\text { cut-off value of loadings }(0.48)\end{array}$ \\
\hline & $\begin{array}{l}\text { 2. During the COVID-19 pandemic, when I } \\
\text { follow up with students, I feel exhausted } \\
\text { and overwhelmed }\end{array}$ & N_Feel2 & Author-developed item \\
\hline & $\begin{array}{l}\text { During the COVID-19 pandemic, I feel } \\
\text { depressed as I am not accustomed to the } \\
\text { new situation of self-isolation. }\end{array}$ & N_Feel3 & Author-developed item \\
\hline & $\begin{array}{l}\text { During the COVID-19 pandemic, I feel } \\
\text { frustrated as I am not accustomed to the } \\
\text { new teaching environment at home with } \\
\text { family disturbance. }\end{array}$ & N_Feel4 & Author-developed item \\
\hline & $\begin{array}{l}\text { During the COVID-19 pandemic, I have a } \\
\text { feeling of anxiety of the possibility of } \\
\text { being infected. }\end{array}$ & N_Feel5 & Author-developed item \\
\hline & $\begin{array}{l}\text { During the COVID-19 pandemic, I am not } \\
\text { able to control my stress and anxiety. }\end{array}$ & N_Feel6 & Author-developed item \\
\hline & $\begin{array}{l}\text { During the COVID-19 pandemic, I } \\
\text { envisioned losing my job and } \\
\text { financial burden. }\end{array}$ & N_Feel7 & Author-developed item \\
\hline & $\begin{array}{l}\text { During the COVID- } 19 \text { pandemic, I get } \\
\text { angry and lose my balance easily because } \\
\text { of the pressure from my workload and } \\
\text { increased family responsibilities. }\end{array}$ & N_Feel8 & Author-developed item \\
\hline & $\begin{array}{l}\text { During the COVID-19 pandemic, I feel } \\
\text { disappointed as I cannot practice my social } \\
\text { life outside my house easily. }\end{array}$ & N_Feel9 & Author-developed item \\
\hline & $\begin{array}{l}\text { 10. During the COVID-19 pandemic, I feel } \\
\text { bored as I cannot practice any sport } \\
\text { activities outside my house. }\end{array}$ & N_Feel10 & Author-developed item \\
\hline
\end{tabular}


Table A1. Cont.

\begin{tabular}{|c|c|c|c|c|}
\hline Latent Variable & \multicolumn{2}{|c|}{ Item/Indicator } & Coding & Remarks \\
\hline \multirow[t]{6}{*}{ Self-efficacy (SEF) } & 1. & $\begin{array}{l}\text { During the COVID-19 pandemic, I am } \\
\text { capable of using online teaching methods } \\
\text { to deliver course content }\end{array}$ & SEF1 & Author-developed item \\
\hline & 2. & $\begin{array}{l}\text { During the COVID- } 19 \text { pandemic, I am able } \\
\text { to use the online teaching methods to } \\
\text { deliver course content }\end{array}$ & SEF2 & Author-developed item \\
\hline & 3. & $\begin{array}{l}\text { During the COVID- } 19 \text { pandemic, I have the } \\
\text { technical background to understand and } \\
\text { use the online teaching methods }\end{array}$ & SEF3 & Author-developed item \\
\hline & 4. & $\begin{array}{l}\text { During the COVID- } 19 \text { pandemic, I possess } \\
\text { the technical skills to use the online } \\
\text { teaching methods }\end{array}$ & SEF4 & Author-developed item \\
\hline & 5. & $\begin{array}{l}\text { During the COVID-19 pandemic, I have the } \\
\text { intellectual capability to understand, learn, } \\
\text { or use online teaching methods }\end{array}$ & SEF5 & Author-developed item \\
\hline & 6. & $\begin{array}{l}\text { During the COVID- } 19 \text { pandemic, I possess } \\
\text { patience to get acquainted with using the } \\
\text { new digital methods to deliver course } \\
\text { content to my students }\end{array}$ & SEF6 & Author-developed item \\
\hline
\end{tabular}

\section{References}

1. Taufiq Hail, G.A. Educational Learning and Teaching Methods' Challenges during Covid-19 Outbreak and a Sudden Transformation towards Totally Digitizing Education. Int. J. Educ. Sci. 2020, 3, 56-57. [CrossRef]

2. Meher, B.K.; Hawaldar, I.T.; Mohapatra, L.; Sarea, A.M. The Impact of COVID-19 on Price Volatility of Crude Oil and Natural Gas Listed on Multi Commodity Exchange of India. Int. J. Energy Econ. Policy 2020, 10, 422-431. [CrossRef]

3. Lopes de Sousa Jabbour, A.B.; Chiappetta Jabbour, C.J.; Hingley, M.; Vilalta-Perdomo, E.L.; Ramsden, G.; Twigg, D. Sustainability of Supply Chains in the Wake of the Coronavirus (COVID-19/SARS-CoV-2) Pandemic: Lessons and Trends. Mod. Supply Chain Res. Appl. 2020, 2, 117-122. [CrossRef]

4. Madero Gómez, S.; Ortiz Mendoza, O.E.; Ramírez, J.; Olivas-Luján, M.R. Stress and Myths Related to the COVID-19 Pandemic's Effects on Remote Work. Manag. Res. J. Iberoam. Acad. Manag. 2020, 18, 401-420. [CrossRef]

5. Baloch, G.M.; Sundarasen, S.; Chinna, K.; Nurunnabi, M.; Kamaludin, K.; Khoshaim, H.B.; Hossain, S.F.A.; AlSukayt, A. COVID19: Exploring Impacts of the Pandemic and Lockdown on Mental Health of Pakistani Students. PeerJ 2021, 9, e10612. [CrossRef] [PubMed]

6. Agarwal, S.; Dewan, J. An Analysis of the Effectiveness of Online Learning in Colleges of Uttar Pradesh during the Covid-19 Lockdown. J. Xi'an Univ. Archit. Technol. 2020, 12, 2957-2963.

7. Nethravathi, P.S.R.; Bai, G.V.; Spulbar, C.; Suhan, M.; Birau, R.; Calugaru, T.; Hawaldar, I.T.; Ejaz, A. Business Intelligence Appraisal Based on Customer Behaviour Profile by Using Hobby Based Opinion Mining in India: A Case Study. Econ. Res.-Ekon. Istraž. 2020, 33, 1889-1908. [CrossRef]

8. Yan, Z. Unprecedented Pandemic, Unprecedented Shift, and Unprecedented Opportunity. Hum. Behav. Emerg. Technol. 2020, 2, 110-112. [CrossRef] [PubMed]

9. Agoramoorthy, G. The Coronavirus Stress: A Reality Check of India's Mental Health Social Agenda. Int. J. Soc. Psychiatry 2020, 66, 623-624. [CrossRef] [PubMed]

10. Zhang, W.; Wang, Y.; Yang, L.; Wang, C. Suspending Classes without Stopping Learning: China's Education Emergency Management Policy in the Covid-19 Outbreak. J. Risk Financ. Manag. 2020, 13, 55. [CrossRef]

11. Rogers, E.M. Diffusion of Innovations, 5th ed.; Free Press A division of Macmillan Publishing, Co., Inc.: New York, NY, USA, 2003; ISBN 0-7432-5823-1.

12. Agarwal, A.; Sharma, S.; Kumar, V.; Kaur, M. Effect of E-Learning on Public Health and Environment during COVID-19 Lockdown. Big Data Min. Anal. 2021, 4, 104-115. [CrossRef]

13. Dodd, R.H.; Dadaczynski, K.; Okan, O.; McCaffery, K.J.; Pickles, K. Psychological Wellbeing and Academic Experience of University Students in Australia during Covid-19. Int. J. Environ. Res. Public. Health 2021, 18, 866. [CrossRef]

14. Naicker, A.; Singh, E.; van Genugten, T. Collaborative Online International Learning (COIL): Preparedness and Experiences of South African Students. Innov. Educ. Teach. Int. 2021, 1-12. [CrossRef]

15. O'Byrne, L.; Gavin, B.; Adamis, D.; Lim, Y.X.; McNicholas, F. Levels of Stress in Medical Students Due to COVID-19. J. Med. Ethics 2021, 47, 383-388. [CrossRef] [PubMed]

16. Tan, C. The Impact of COVID-19 on Student Motivation, Community of Inquiry and Learning Performance. Asian Educ. Dev. Stud. 2020, 10, 308-321. [CrossRef]

17. Bensaid, B.; Brahimi, T. Coping with Covid-19: Higher education in the GCC countries. In Research and Innovation Forum 2020; Visvizi, A., Lytras, M.D., Aljohani, N.R., Eds.; Springer Proceedings in Complexity; Springer International Publishing: Cham, Switzerland, 2021; pp. 137-153. ISBN 978-3-030-62065-3.

18. Webb, A.; McQuaid, R.W.; Webster, C.W.R. Moving Learning Online and the COVID-19 Pandemic: A University Response. World J. Sci. Technol. Sustain. Dev. 2021, 18, 1-19. [CrossRef] 
19. Odriozola-González, P.; Planchuelo-Gómez, Á.; Irurtia, M.J.; de Luis-García, R. Psychological Effects of the COVID-19 Outbreak and Lockdown among Students and Workers of a Spanish University. Psychiatry Res. 2020, 290, 113108. [CrossRef] [PubMed]

20. Ali, L.; Dmour, N.A.H.H.A. The Shift to Online Assessment Due to Covid-19: An Empirical Study of University Students, Behaviour and Performance, in the Region of Uae. Int. J. Inf. Educ. Technol. 2021, 11, 220-228. [CrossRef]

21. Moussa, N.M.; Ali, W.F. Exploring the Relationship between Students' Academic Success and Happiness Levels in the Higher Education Settings during the Lockdown Period of Covid-19. Psychol. Rep. 2021, 003329412199456. [CrossRef] [PubMed]

22. Al-Taweel, D.; Al-Haqan, A.; Bajis, D.; Al-Bader, J.; Al-Taweel, A.M.; Al-Awadhi, A.; Al-Awadhi, F. Multidisciplinary Academic Perspectives during the COVID-19 Pandemic. Int. J. Health Plann. Manag. 2020, 35, 1295-1301. [CrossRef]

23. Alghamdi, A.K.; Aldossary, A.T.; Deraney, P. Graduate Students' Perceptions of and Recommendations Pursuant to Saudi Arabia's COVID 19 "Stay-at-Home" Initiative. Cypriot J. Educ. Sci. 2021, 16, 687-702. [CrossRef]

24. Zia, A. Exploring Factors Influencing Online Classes Due to Social Distancing in COVID-19 Pandemic: A Business Students Perspective. Int. J. Inf. Learn. Technol. 2020, 37, 197-211. [CrossRef]

25. Sarea, A.; Alhadrami, A.; Taufiq-Hail, G.A. COVID-19 and Digitizing Accounting Education: Empirical Evidence from GCC. PSU Res. Rev. 2021, 5, 68-83. [CrossRef]

26. Tsui, A.B.M.; Chan, C.K.K.; Harfitt, G.; Leung, P. Crisis and Opportunity in Teacher Preparation in the Pandemic: Exploring the "Adjacent Possible". J. Prof. Cap. Community 2020, 5, 237-245. [CrossRef]

27. Sahu, P. Closure of Universities Due to Coronavirus Disease 2019 (Covid-19): Impact on Education and Mental Health of Students and Academic Staff. Cureus 2020, 4, e7541. [CrossRef] [PubMed]

28. Unsworth, K. Human Relations Virtual Special Issue: Virtual Working. Hum. Relat. 2020, 73, 1036-1040. [CrossRef]

29. López López, L.; McCaw, C.T.; Di Biase, R.; McKernan, A.; Rudolph, S.; Galatis, A.; Dulfer, N.; Gerrard, J.; McKinley, E.; McLeod, J.; et al. The Quarantine Archives: Educators in "Social Isolation". Hist. Educ. Rev. 2020, 49, 195-213. [CrossRef]

30. Alawamleh, M.; Al-Twait, L.M.; Al-Saht, G.R. The Effect of Online Learning on Communication between Instructors and Students during Covid-19 Pandemic. Asian Educ. Dev. Stud. 2020. ahead-of-print. [CrossRef]

31. Bisht, R.K.; Jasola, S.; Bisht, I.P. Acceptability and Challenges of Online Higher Education in the Era of COVID-19: A Study of Students' Perspective. Asian Educ. Dev. Stud. 2020. ahead-of-print. [CrossRef]

32. Easton, S.S. Clarifying the Instructor's Role in Online Distance Learning. Commun. Educ. 2003, 52, 87-105. [CrossRef]

33. Makrakis, V.; Kostoulas-Makrakis, N. Responsibility and Co-Responsibility in Light of Covid-19 and Education for Sustainability through an Aristotelian Lens. Sustain. Clim. Change 2021, 14, 158-165. [CrossRef]

34. Baumann, T.; Mantay, K.; Swanger, A.; Saganski, G.; Stepke, S. Education and Innovation Management: A Contradiction? How to Manage Educational Projects If Innovation Is Crucial for Success and Innovation Management Is Mostly Unknown. Procedia Soc. Behav. Sci. 2016, 226, 243-251. [CrossRef]

35. Podmetina, D.; Soderquist, K.E.; Petraite, M.; Teplov, R. Developing a Competency Model for Open Innovation: From the Individual to the Organisational Level. Manag. Decis. 2018, 56, 1306-1335. [CrossRef]

36. Ramirez-Montoya, M.S. Challenges for Open Education with Educational Innovation: A Systematic Literature Review. Sustainability 2020, 12, 7053. [CrossRef]

37. Howells, J.; Ramlogan, R.; Cheng, S. Universities in an Open Innovation System: A UK Perspective. Int. J. Entrep. Behav. Res. 2012, 18, 440-456. [CrossRef]

38. Lichtenthaler, U. Past Research, Current Debates, and Future Directions. Acad. Manag. Perspect. 2011, 25 , 75-93.

39. Arslan, M.; Roudaki, J. Examining the Role of Employee Engagement in the Relationship between Organisational Cynicism and Employee Performance. Int. J. Sociol. Soc. Policy 2019, 39, 118-137. [CrossRef]

40. Aşkun, V.; ÇiZel, R.; Ajanovic, E. Comparative Analysis of Factors Affecting Employee Performance According to Job Performance Measurement Method: The Case of Performing Artists. Ege Akad. Bakis Ege Acad. Rev. 2021, 21, 29-45. [CrossRef]

41. Cronin, B. Performance Measurement and Information Management. Aslib Proc. 1982, 34, 227-236. [CrossRef]

42. Saleem, M.A.; Bhutta, Z.M.; Nauman, M.; Zahra, S. Enhancing Performance and Commitment through Leadership and Empowerment: An Emerging Economy Perspective. Int. J. Bank Mark. 2019, 37, 303-322. [CrossRef]

43. Koopmans, L.; Bernaards, C.M.; Hildebrandt, V.H.; de Vet, H.C.W.; van der Beek, A.J. Construct Validity of the Individual Work Performance Questionnaire. J. Occup. Environ. Med. 2014, 56, 331-337. [CrossRef] [PubMed]

44. Sonnentag, S.; Frese, M. Performance concepts and performance theory. In Psychological Management of Individual Performance; Sonnentag, S., Ed.; John Wiley \& Sons, Ltd.: Chichester, UK, 2005; pp. 1-25. ISBN 978-0-470-01341-0.

45. Tanhan, A. Acceptance and Commitment Therapy with Ecological Systems Theory: Addressing Muslim Mental Health Issues and Wellbeing. J. Posit. Psychol. Wellbeing 2019, 3, 197-219. [CrossRef]

46. Arslan, G.; Yıldırım, M.; Tanhan, A.; Buluş, M.; Allen, K.-A. Coronavirus Stress, Optimism-Pessimism, Psychological Inflexibility, and Psychological Health: Psychometric Properties of the Coronavirus Stress Measure. Int. J. Ment. Health Addict. 2020, 1-17. [CrossRef] [PubMed]

47. Yao, H.; Chen, J.-H.; Xu, Y.-F. Rethinking Online Mental Health Services in China during the COVID-19 Epidemic. Asian J. Psychiatry 2020, 50, 102015. [CrossRef] [PubMed]

48. Zhang, J.; Wu, W.; Zhao, X.; Zhang, W. Recommended Psychological Crisis Intervention Response to the 2019 Novel Coronavirus Pneumonia Outbreak in China: A Model of West China Hospital. Precis. Clin. Med. 2020, 3, 3-8. [CrossRef] 
49. Pekrun, R.; Goetz, T.; Frenzel, A.C.; Barchfeld, P.; Perry, R.P. Measuring Emotions in Students' Learning and Performance: The Achievement Emotions Questionnaire (AEQ). Contemp. Educ. Psychol. 2011, 36, 36-48. [CrossRef]

50. Pekrun, R.; Goetz, T.; Titz, W.; Perry, R.P. Academic Emotions in Students' Self-Regulated Learning and Achievement: A Program of Qualitative and Quantitative Research. Educ. Psychol. 2002, 37, 91-105. [CrossRef]

51. Bao, Y.; Sun, Y.; Meng, S.; Shi, J.; Lu, L. 2019-NCoV Epidemic: Address Mental Health Care to Empower Society. The Lancet 2020, 395, e37-e38. [CrossRef]

52. Wang, C.; Pan, R.; Wan, X.; Tan, Y.; Xu, L.; Ho, C.S.; Ho, R.C. Immediate Psychological Responses and Associated Factors during the Initial Stage of the 2019 Coronavirus Disease (COVID-19) Epidemic among the General Population in China. Int. J. Environ. Res. Public. Health 2020, 17, 1729. [CrossRef] [PubMed]

53. Pekrun, R. The Impact of Emotions on Learning and Achievement: Towards a Theory of Cognitive/Motivational Mediators. Appl. Psychol. 1992, 4, 359-376. [CrossRef]

54. Nes, L.S.; Segerstrom, S.C. Dispositional Optimism and Coping: A Meta-Analytic Review. Personal. Soc. Psychol. Rev. 2006, 10, 235-251. [CrossRef] [PubMed]

55. Nes, L.S. Optimism, Pessimism, and Stress. In Stress: Concepts, Cognition, Emotion, and Behavior; Fink, G., Ed.; Handbook of Stress Series; Elsevier: Amsterdam, The Netherlands, 2016; Volume 1, pp. 405-411, ISBN 978-0-12-800951-2.

56. Bruque, S.; Moyano, J.; Piccolo, R. OCB and External-Internal Social Networks: Effects on Individual Performance and Adaptation to Change. Int. J. Hum. Resour. Manag. 2016, 27, 1-22. [CrossRef]

57. Bandura, A. Self-Efficacy: Toward a Unifying Theory of Behavioral Change. Psychol. Rev. 1977, 84, 191-215. [CrossRef]

58. Bandura, A. (Ed.) Self-Efficacy in Changing Societies; Cambridge University Press: Cambridge, UK, 1995; ISBN 978-0-521-47467-2.

59. Schunk, D.H. Self-Efficacy, Motivation, and Performance. J. Appl. Sport Psychol. 1995, 7, 112-137. [CrossRef]

60. Stajkovic, D.; Luthans, F. Social Cognitive Theory and Self-Efficacy: Goin beyond Traditional Motivational and Behavioral Approaches. Organ. Dyn. 1998, 26, 62-74. [CrossRef]

61. Hampel, R.; Stickler, U. New Skills for New Classrooms: Training Tutors to Teach Languages Online. Comput. Assist. Lang. Learn. 2005, 18, 311-326. [CrossRef]

62. Luthans, F.; Peterson, S.J. Employee Engagement and Manager Self-efficacy. J. Manag. Dev. 2002, 21, 376-387. [CrossRef]

63. Schmidt, A.M.; DeShon, R.P. The Moderating Effects of Performance Ambiguity on the Relationship between Self-Efficacy and Performance. J. Appl. Psychol. 2010, 95, 572-581. [CrossRef] [PubMed]

64. Lee, P.C.; Mao, Z. The Relation among Self-Efficacy, Learning Approaches, and Academic Performance: An Exploratory Study. J. Teach. Travel Tour. 2016, 16, 178-194. [CrossRef]

65. Bakar, N.M.A.; Tahir, I.M. Applying Multiple Linear Regression and Neural Network to Predict Bank Performance. Int. Bus. Res. 2009, 2, 176. [CrossRef]

66. Chong, A.Y.-L. A Two-Staged SEM-Neural Network Approach for Understanding and Predicting the Determinants of mCommerce Adoption. Expert Syst. Appl. 2013, 40, 1240-1247. [CrossRef]

67. Chiang, W.K.; Zhang, D.; Zhou, L. Predicting and Explaining Patronage Behavior toward Web and Traditional Stores Using Neural Networks: A Comparative Analysis with Logistic Regression. Decis. Support Syst. 2006, 41, 514-531. [CrossRef]

68. Sim, J.-J.; Tan, G.W.-H.; Wong, J.C.J.; Ooi, K.-B.; Hew, T.-S. Understanding and Predicting the Motivators of Mobile Music Acceptance-A Multi-Stage MRA-Artificial Neural Network Approach. Telemat. Inform. 2014, 31, 569-584. [CrossRef]

69. Sharma, S.K. Integrating Cognitive Antecedents into TAM to Explain Mobile Banking Behavioral Intention: A SEM-Neural Network Modeling. Inf. Syst. Front. 2019, 21, 815-827. [CrossRef]

70. Chong, A.Y.-L. Predicting M-Commerce Adoption Determinants: A Neural Network Approach. Expert Syst. Appl. 2013, 40, 523-530. [CrossRef]

71. Liébana-Cabanillas, F. A SEM-Neural Network Approach for Predicting Antecedents of m-Commerce Acceptance. Int. J. Inf. Manag. 2017, 37, 14-24. [CrossRef]

72. Chan, F.T.S.; Chong, A.Y.L. A SEM-Neural Network Approach for Understanding Determinants of Interorganizational System Standard Adoption and Performances. Decis. Support Syst. 2012, 54, 621-630. [CrossRef]

73. Hew, T.-S.; Leong, L.-Y.; Ooi, K.-B.; Chong, A.Y.-L. Predicting Drivers of Mobile Entertainment Adoption: A Two-Stage SEMArtificial-Neural-Network Analysis. J. Comput. Inf. Syst. 2016, 56, 352-370. [CrossRef]

74. Sharma, S.K.; Govindaluri, S.M.; Al Balushi, S.M. Predicting Determinants of Internet Banking Adoption: A Two-Staged Regression-Neural Network Approach. Manag. Res. Rev. 2015, 38, 750-766. [CrossRef]

75. Alam, M.Z.; Hu, W.; Kaium, M.A.; Hoque, M.R.; Alam, M.M.D. Understanding the Determinants of MHealth Apps Adoption in Bangladesh: A SEM-Neural Network Approach. Technol. Soc. 2020, 61, 101255. [CrossRef]

76. Liébana-Cabanillas, F.; Marinkovic, V.; Ramos de Luna, I.; Kalinic, Z. Predicting the Determinants of Mobile Payment Acceptance: A Hybrid SEM-Neural Network Approach. Technol. Forecast. Soc. Change 2018, 129, 117-130. [CrossRef]

77. Sabbir, M.M.; Islam, M.; Das, S. Understanding the Determinants of Online Pharmacy Adoption: A Two-Staged SEM-Neural Network Analysis Approach. J. Sci. Technol. Policy Manag. 2020, 12, 666-687. [CrossRef]

78. Svozil, D.; Kvasnicka, V.; Pospichal, J. Introduction to Multi-Layer Feed-Forward Neural Networks. Chemom. Intell. Lab. Syst. 1997, 39, 43-62. [CrossRef]

79. Ooi, K.-B.; Tan, G.W.-H. Mobile Technology Acceptance Model: An Investigation Using Mobile Users to Explore Smartphone Credit Card. Expert Syst. Appl. 2016, 59, 33-46. [CrossRef] 
80. Yadav, R.; Sharma, S.K.; Tarhini, A. A Multi-Analytical Approach to Understand and Predict the Mobile Commerce Adoption. J. Enterp. Inf. Manag. 2016, 29, 222-237. [CrossRef]

81. Leong, L.-Y.; Hew, T.-S.; Ooi, K.-B.; Tan, G.W.-H. Predicting Actual Spending in Online Group Buying-An Artificial Neural Network Approach. Electron. Commer. Res. Appl. 2019, 38, 100898. [CrossRef]

82. Taylor, S.; Todd, P.A. Understanding Information Technology Usage: A Test of Competing Models. Inf. Syst. Res. 1995, 6, 144-176. [CrossRef]

83. Zolait, A.H.S. The Nature and Components of Perceived Behavioural Control as an Element of Theory of Planned Behaviour. Behav. Inf. Technol. 2014, 33, 65-85. [CrossRef]

84. Ringle, C.M.; Wende, S.; Becker, J.M. Smart PLS (M3); SmartPLS GmbH: Boenningstedt, Germany, 2015.

85. Sekaran, U. Research Methods for Business: A Skill Building Approach; 4th ed.; John Willey \& Sons, Inc.: New York, NY, USA, 2003; ISBN 0-471-20366-1.

86. Faul, F.; Erdfelder, E.; Buchner, A.; Lang, A.-G. Statistical Power Analyses Using G*Power 3.1: Tests for Correlation and Regression Analyses. Behav. Res. Methods 2009, 41, 1149-1160. [CrossRef]

87. Hair, J.F.; Sarstedt, M.; Hopkins, L.; Kuppelwieser, G.V. Partial Least Squares Structural Equation Modeling (PLS-SEM): An Emerging Tool in Business Research. Eur. Bus. Rev. 2014, 26, 106-121. [CrossRef]

88. Podsakoff, P.M.; MacKenzie, S.B.; Lee, J.-Y.; Podsakoff, N.P. Common Method Biases in Behavioral Research: A Critical Review of the Literature and Recommended Remedies. J. Appl. Psychol. 2003, 88, 879-903. [CrossRef] [PubMed]

89. Mooi, E.; Sarstedt, M. Factor Analysis. In A Concise Guide to Market Research; Springer: Berlin/Heidelberg, Germany, 2010; pp. 201-236, ISBN 978-3-642-12540-9.

90. Hair, J.F.; Ringle, C.M.; Sarstedt, M. PLS-SEM: Indeed a Silver Bullet. J. Mark. Theory Pract. 2011, 19, 139-152. [CrossRef]

91. Hair, J.F.; Hult, G.T.M.; Ringle, C.M.; Sarstedt, M. A Primer on Partial Least Squares Structural Equation Modeling (PLS-SEM), 2nd ed.; SAGE Publications, Inc.: London, UK, 2017; ISBN 978-1-4833-7744-5.

92. Kline, R.B. Principles and Practice of Structural Equation Modeling, 3rd ed.; Methodology in the social sciences; Guilford Press: New York, NY, USA, 2011; ISBN 978-1-60623-877-6.

93. Field, A. Discovering Statistics Using SPSS, 3rd ed.; SAGE Publications: London, UK, 2009; ISBN 978-1-84787-906-6.

94. Chin, W.W. The partial least squares approach to structural equation modeling. In Modern Methods for Business Research; Marcoulides, G.A., Ed.; Lawrence Erlbaum Associates: Mahwah, NJ, USA, 1998; pp. 295-336, ISBN 0-8058-2677-7.

95. Ramayah, T.; Soto-Acosta, P.; Colomo-Palacios, R.; Gopi, M.; Popa, S. Explaining the Adoption of Internet Stock Trading in Malaysia: Comparing Models. Asian J. Technol. Innov. 2014, 22, 131-151. [CrossRef]

96. Fornell, C.; Larker, D.F. Evaluating Structural Equation Models with Unobservable Variables and Measurement Error. J. Mark. Res. 1981, 18, 39-50. [CrossRef]

97. Sarstedt, M.; Ringle, C.M.; Smith, D.; Reams, R.; Hair, J.F. Partial Least Squares Structural Equation Modeling (PLS-SEM): A Useful Tool for Family Business Researchers. J. Fam. Bus. Strategy 2014, 5, 105-115. [CrossRef]

98. Zimmerman, B.J.; Bandura, A.; Martinez-Pons, M. Self-Motivation for Academic Attainment: The Role of Self-Efficacy Beliefs and Personal Goal Setting. Am. Educ. Res. J. 1992, 29, 663-676. [CrossRef]

99. Leong, L.; Ooi, K.; Chong, A.Y.; Lin, B. Modeling the Stimulators of the Behavioral Intention to Use Mobile Entertainment: Does Gender Really Matter? Comput. Hum. Behav. 2013, 29, 2109-2121. [CrossRef]

100. Leong, L.-Y.; Hew, T.-S.; Ooi, K.-B.; Chong, A.Y.-L. Predicting the Antecedents of Trust in Social Commerce-A Hybrid Structural Equation Modeling with Neural Network Approach. J. Bus. Res. 2020, 110, 24-40. [CrossRef]

101. Tan, G.W.-H.; Ooi, K.-B.; Chong, S.-C.; Hew, T.-S. NFC Mobile Credit Card: The next Frontier of Mobile Payment? Telemat. Inform. 2014, 31, 292-307. [CrossRef] 